\title{
Design and Calibration of a Flowfield Survey Rake for Inlet Flight Research
}

\author{
Darin C. Flynn ${ }^{*}$, Nalin A. Ratnayake ${ }^{\dagger}$, and Michael Frederick* \\ NASA Dryden Flight Research Center, Edwards, California, 93523
}

\begin{abstract}
The Propulsion Flight Test Fixture at the NASA Dryden Flight Research Center is a unique test platform available for use on NASA's F-15B aircraft, tail number 836, as a modular host for a variety of aerodynamics and propulsion research. For future flight data from this platform to be valid, more information must be gathered concerning the quality of the airflow underneath the body of the F-15B at various flight conditions, especially supersonic conditions. The flow angularity and Mach number must be known at multiple locations on any test article interface plane for measurement data at these locations to be valid. To determine this prerequisite information, flight data will be gathered in the Rake Airflow Gauge Experiment using a custom-designed flowfield rake to probe the airflow underneath the $F-15 B$ at the desired flight conditions. This paper addresses the design considerations of the rake and probe assembly, including the loads and stress analysis using analytical methods, computational fluid dynamics, and finite element analysis. It also details the flow calibration procedure, including the completed wind-tunnel test and posttest data reduction, calibration verification, and preparation for flight-testing.
\end{abstract}

\section{Nomenclature}

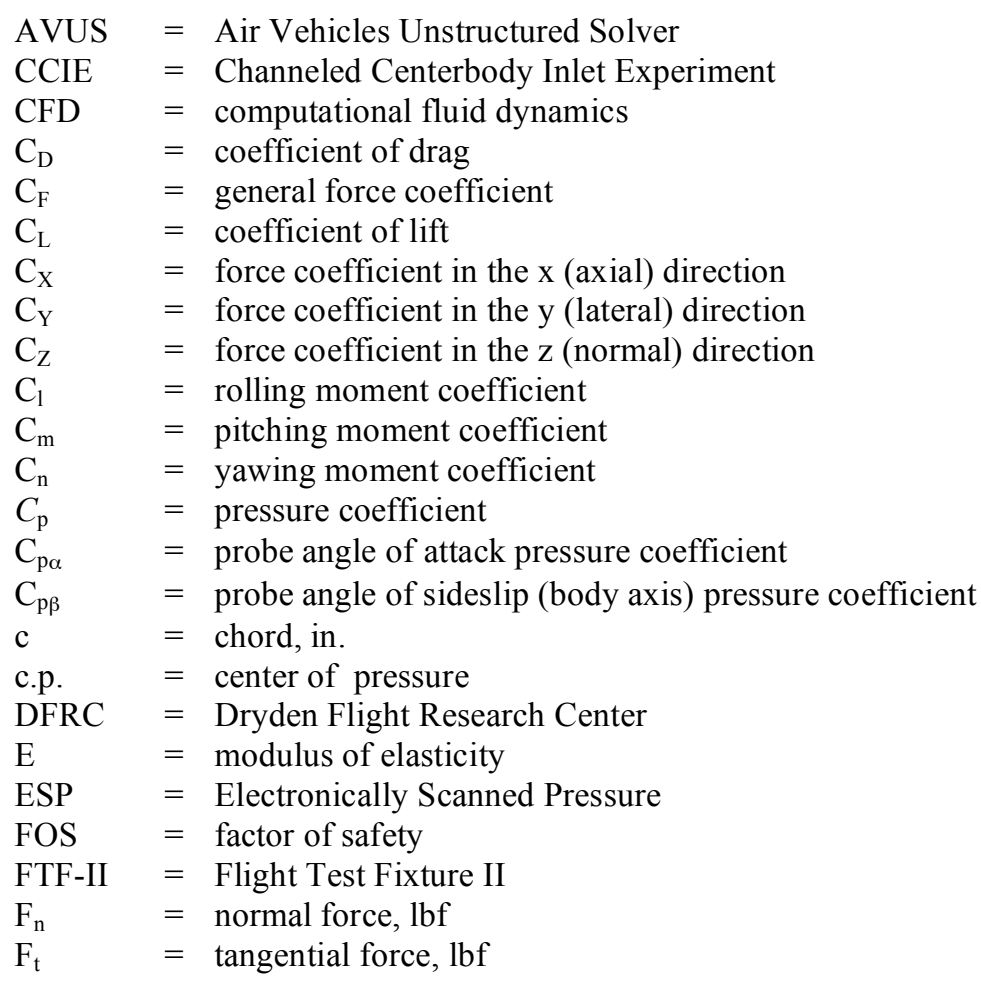

\footnotetext{
* Aerospace Engineer, Aerodynamics and Propulsion Branch, M/S 4840B.

$\dagger$ Aerospace Engineer, Aerodynamics and Propulsion Branch, M/S 4840B, AIAA Member.

* Aerospace Engineer, Aerodynamics and Propulsion Branch, M/S 2228, AIAA Member.
} 


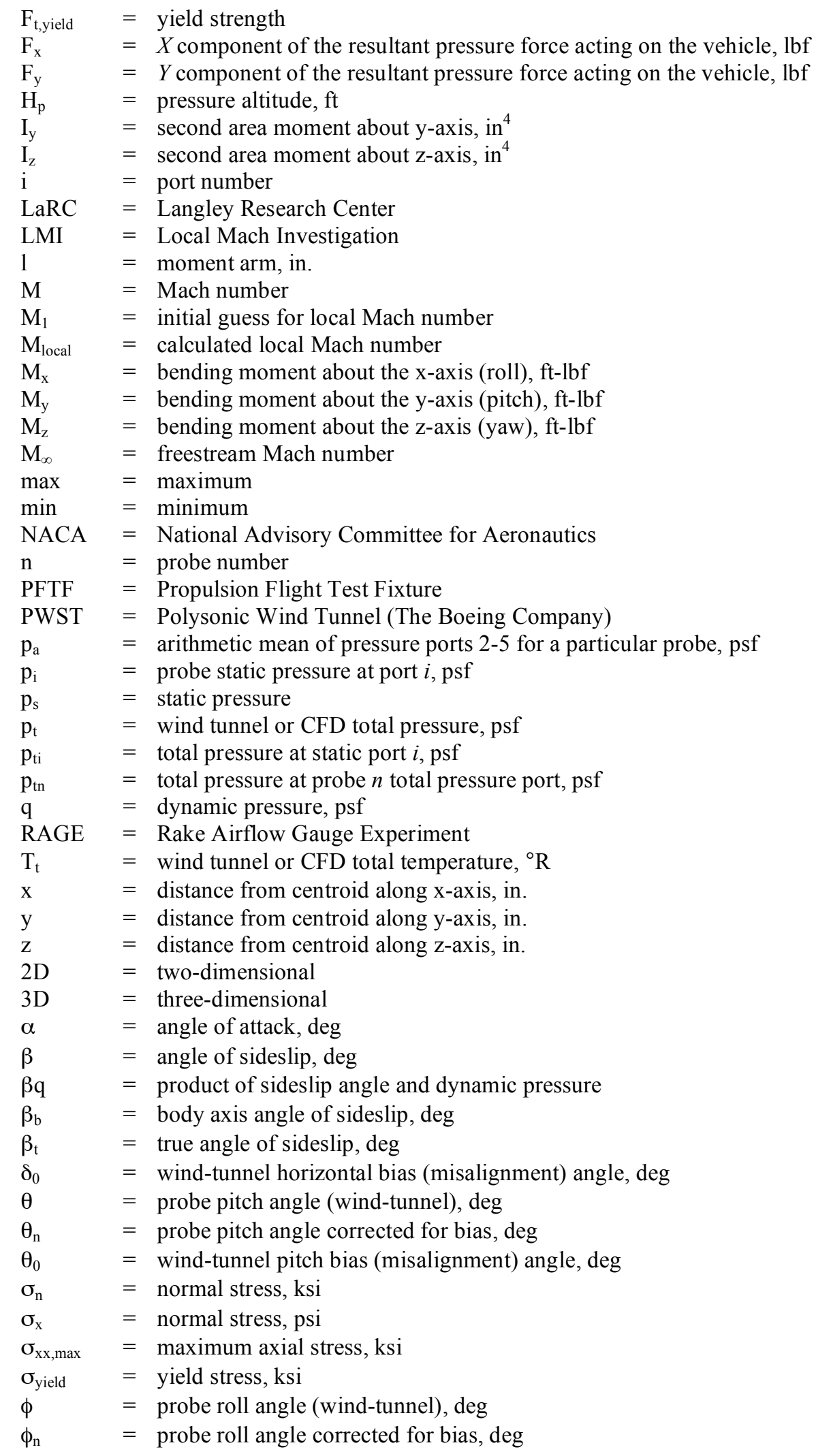




\section{Introduction}

The Propulsion Flight Test Fixture (PFTF) system at the National Aeronautics and Space Administration (NASA) Dryden Flight Research Center (DFRC) provides an innovative and cost-effective method of flight-testing advanced propulsion system concepts and components in a relevant environment using an F-15B flight testbed aircraft, tail number 836. The F-15B (The Boeing Company Chicago, Illinois) is a two-seat trainer version of the F-15 high-performance, supersonic air superiority fighter aircraft. It is powered by two Pratt \& Whitney (Hartford, Connecticut) F100-PW-100 afterburning turbofan engines. The PFTF attaches to the centerline pylon of the aircraft and has an integrated six-axis force balance for flighttesting propulsion experiments. ${ }^{1}$ A photograph of the F-15B in flight with the PFTF pylon attached is presented as Fig. 1.

The PFTF has undergone two previous flight validation test phases:

1. The Local Mach Investigation (LMI) flights, in which an air-data boom was attached to a cylinder with a conical nose cap. ${ }^{2}$ This flight-test phase quantified the local Mach number and the local flow angle at a single point under the F-15B PFTF.

2. The Cone Drag Experiment, in which the cylinder with conical nosecap assembly was tested in order to validate the PFTF's integral six-axis force balance ${ }^{3}$

The next experiment planned for the PFTF is the flight test of the Channeled Centerbody Inlet Experiment (CCIE) $;{ }^{4}$ however, for the flight data from this test to be valid, more information is required to quantify the quality of the airflow through the aerodynamic interface plane of the inlet, which is the plane facing into the airflow at the planned location of the tip of the inlet centerbody. The flow angularity and Mach number must be known at multiple locations on the interface plane. Flight data will be gathered using a custom-designed flowfield rake to probe the airflow underneath the F-15B in front of the PFTF at the desired flight conditions: Mach 1.5 at an altitude of 29,500 ft.

This paper addresses the design considerations of the rake and probe assembly, including the aerodynamic loads and stress analysis using analytical methods, computational fluid dynmics (CFD), and finite element analysis. The paper also details the calibration procedure, including the completed windtunnel test and post-test data reduction, calibration verification, and preparation for flight-testing.

Successful completion of the Rake Airflow Gauge Experiment (RAGE) research flights will provide current and future PFTF experiments with accurate flowfield models of inlet conditions and other flow properties prior to flight-testing. This is a significant upgrade to the PFTF's capability as a test platform available to the aerospace research community.

\section{Design of Rake Geometry}

The RAGE consists of the flowfield survey rake, which is an array of nine five-hole conical probes (shown in Fig. 2) mounted in a cross configuration to the LMI cylinder and boom hardware. The pressure lines from each probe feed through the rake structure to emerge from the rear, where they are connected to pressure transducers through the PFTF. A depiction of the flowfield rake mounted onto the PFTF and boom is provided in Fig. 3. The structure to which the boom is attached is referred to as the crayon.

The span of the rake is 9.5 inches and the chord is 2.5 inches with a maximum thickness of 0.375 inches. The probes extend 3.0 inches past the leading edge of the rake. The span of 9.5 inches was chosen to represent the size of a typical experiment on the PFTF. The geometry was chosen to accommodate pressure tube routing, bending stress constraints, machining requirements, and flow blockage concerns in the wind tunnel.

The rake is a two-piece design, comprised of a forward and a rear section that are bolted together. The rake is made from 7075-T6 Aluminum (AL 7075-T6), chosen for its high specific strength and ease of machining. A channel between the forward and rear sections allows routing of pressure tubing.

The RAGE probes are of standard shape, consisting geometrically of a long cylinder with a conical cap at the end and a small opening at the tip of the cap, which faces into the airflow. The dimensions of the cylinder are 3.65 inches long and a 0.125 -inch diameter; the cap is a $60^{\circ}$ right circular cone with a 0.015 -

inch diameter flat normal surface at the stagnation point to accommodate the pitot line. Only the forward 3.0 inches are exposed to the airflow.

A schematic showing the probe and port numbering convention is shown in Fig. 4. 


\section{Loads and Stress Analysis}

Loads and stress analyses were performed on the components of the RAGE design as well as on the assembly as a whole in order to determine whether the hardware possessed adequate structural margins of safety for wind-tunnel testing and flight. Inertial loads were ignored in these analyses because inertial loads act opposite to the aerodynamic loads. Thus, the worst-case condition actually occurs when the inertial loads are small. Dynamic loads analysis showed that the RAGE and boom assembly response was similar to that of previously-flown flight experiments on the F-15B's centerline pylon, and that existing F-15B flight-test envelopes at DFRC would provide sufficient margins of safety.

\section{A. Rake Loads and Stress}

The aerodynamic loads analysis for the rake was completed in two steps. First, preliminary calculations were performed using experimental data from a wedge in supersonic flow. Second, a more detailed two-dimensional (2D) CFD analysis was completed for verification. During the loads analysis only worst-case scenarios were assumed. Standard atmospheric conditions were used when calculating dynamic pressure and total pressure.

\section{Rake Loads Overview and Setup}

The rake was treated as a $2 \mathrm{D}$ cross-section in supersonic flow for the CFD analysis, in order to determine the pressure forces and moments per unit span of the rake. The 2D approximation was expected to give the most conservative results because such methods do not take three-dimensional (3D) flow relief effects into account. The actual forces seen in flight were expected to be less than predicted. An inviscid Euler solution was used because viscous forces are significantly less than pressure forces at the highest dynamic pressure flight condition. Figure 5 shows the estimated local conditions at the test points for flight and wind-tunnel tests; black points represent flight-test conditions, and green points show the conditions during the wind-tunnel calibration.

The worst-case loading scenario in flight is the condition with the highest dynamic pressure (1130 psf), which occurs at Mach 1.6 at an altitude of 30,000 ft. Because of wind-tunnel constraints, however, the Mach 1.5 case was tested in the wind tunnel at an equivalent pressure altitude of $20,000 \mathrm{ft}$ and a dynamic pressure of 1532.9 psf. At this condition, the aerodynamic loading will exceed the loading expected in flight-testing by approximately $400 \mathrm{psf}$, or roughly $30 \%$; it is therefore prudent to use this condition as the worst-case condition. The highest angle of attack expected in flight, and to be tested in the wind tunnel, is $10^{\circ}$; however, an angle of attack $(\alpha)$ of $20^{\circ}$ will be used as the worst-case design condition to make the rake still more robust.

\section{Empirical Calculations for Rake Loads}

Low-order calculations were performed as a tool to later verify the CFD analysis. These analyses were based on normal and tangential force coefficients taken from data in Ref. 5, where the coefficients are determined for an $8.2^{\circ}$ lifting wedge at Mach 1.4 and values of $\alpha$ from $0^{\circ}$ to $11^{\circ}$. The data start to level off when $\alpha$ nears $11^{\circ}$, so the coefficients at $\alpha=11^{\circ}$ are used. The geometry and flow conditions considered are not exactly the same, but the results represent a good first approximation for the rake design and serve as a reality check for the CFD analysis.

The section tangential and normal force coefficients are 0.04 and 0.8 , respectively. The coefficients were normalized with respect to chord length, so the results represent a force per unit span.

The resulting normal and axial forces per unit length are given by the standard equation from force coefficients, as shown in Eq. (1):

$$
F / l=C_{F} q c
$$

where $\mathrm{F}$ is the force (normal or tangential), $\mathrm{C}_{\mathrm{F}}$ is the force coefficient, $\mathrm{q}$ is the dynamic pressure, and $\mathrm{c}$ is the chord length in the streamwise direction. From this we calculate:

$$
F_{n} / l=C_{n} q c=255^{l b f} / f t
$$




$$
F_{t} / l=C_{t} q c=13^{l b f} / f t
$$

It is also worth noting that from Ref. 5, the predicted center of pressure will be at approximately $45 \%$ chord.

\section{Computational Fluid Dynamics Analysis of Rake Loads}

A 2D grid was generated using Gridgen ${ }^{\circledR}$ (Pointwise, Inc., Fort Worth, Texas). The grid is a structured C-mesh with $213 \times 5$ grid points. The grid was sized to capture pressure gradients near the surface and contain the bow shock within the outflow boundary. The boundary conditions were specified as freestream, outflow, and viscous wall, for the inflow, outflow, and wall boundaries, respectively. Figure 6 shows the completed grid.

The WIND-US2 flow solver, a newer version of the code formerly known as NPARC, was chosen to run the analysis. Convergence based on pressure forces and moments was reached after approximately 1000 iterations. Figure 7 shows a pressure contour plot created in FieldView ${ }^{\mathrm{TM}}$ (Intelligent Light, Rutherford, New Jersey) for the maximum dynamic pressure condition.

The shock impinges on the inflow boundary and causes a slight disturbance; however the effect does not propagate to the surface of the rake. A larger computational domain would have prevented this, but it is unlikely that the results would change, as the pressure forces on the surface were not affected by the anomaly.

The flow characteristics are as expected. There is a separated bow shock along with a subsonic highpressure region near the leading edge. Note also the large expansion fan on the leeward surface, in which the flow expansion causes pressures lower than freestream conditions. This pressure gradient from lower to upper surface is the largest contributor to the normal force resultant, and the axial load limit is large enough that the viscous force contribution along that axis is insignificant; as such, viscous forces can be ignored for this analysis.

Integrating the pressures over the respective surfaces resulted in the following forces:

$$
\begin{aligned}
& F_{n} / l=328^{l b f} / f t \\
& F_{t} / l=33^{l b f} / f t \\
& M_{y} / l=28 l b f
\end{aligned}
$$

The center of pressure was calculated to be at $41 \%$ chord.

\section{Rake Loads Summary}

The standard stress calculations can now be compared with the CFD-calculated loads to provide a reality check for the latter. The comparison is shown in Table 1. All of the forces computed from CFD analysis are higher than the forces calculated using the methods contained in National Advisory Committee

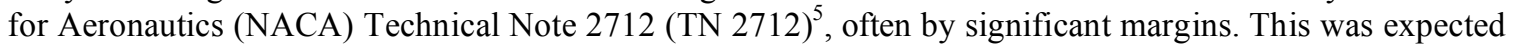
from our aforementioned assumption that a $2 \mathrm{D}$ analysis will yield higher forces and thus be more conservative. The analysis using the methods contained in TN 2712 is a simplified analysis that is intended only to give a rough estimate of the loads. The CFD analysis was intentionally designed with built-in conservatism, and will therefore be used in the stress analysis.

\section{Rake Stress Analysis Overview}

As in the loads analysis, the first steps in the stress analysis were standard stress analysis calculations. Later, more detailed analysis was completed using the Solidworks ${ }^{\circledR}$ COSMOSWorks ${ }^{\mathrm{TM}}$ finite element method. The CFD-calculated loads were used for the stress analysis. The rake was to be designed to a minimum factor of safety (FOS) of 2.25 over yield stress.

For the finite element analysis, the rake was treated as two pieces of material bonded together along the interface plane, disregarding the bolts. The transverse shear stress acting along the mounting plane and reacted by the bolts was calculated using standard stress analysis methods. The material properties at the highest total temperature expected in flight were used. This condition occurs at Mach 1.9 and an altitude of 
$30,000 \mathrm{ft}$, in freestream conditions where the total temperature is $679^{\circ} \mathrm{R}$. The material properties from Ref. 6 are shown in Table 2.

\section{Analytical Calculations of Rake Stress}

Standard stress equations were used to determine the bending stress and the transverse shear stress reacted by the bolts. Classical stress analysis methods were used as described in Ref. 7. Stress risers at the bolt holes were not calculated by hand; it was assumed that if yield stress was exceeded, the surrounding material would be ductile enough to relieve the stress.

To calculate the bending stresses, one arm of the rake was modeled as a cantilevered beam. The forces from the CFD analysis were used to determine the moment at the root. Classical stress analysis was then used to calculate the maximum normal stress, which occurs at the root of the arm.

The formulation for compound bending stress of a cantilevered beam is shown in Eq. (2):

$$
\sigma_{x}=\frac{M_{y} z}{I_{y}}-\frac{M_{z} y}{I_{z}},
$$

where $\mathrm{x}$ is in the direction of the span, $\mathrm{y}$ is in the normal direction, and $\mathrm{z}$ is in the chord direction. $\mathrm{I}_{\mathrm{y}}$ and $\mathrm{I}_{\mathrm{z}}$ were found using the solid model created in Solidworks to be $\mathrm{I}_{\mathrm{y}}=0.20127767 \mathrm{in}^{4}$ and $\mathrm{I}_{\mathrm{z}}=0.00600179 \mathrm{in}^{4}$. A short numerical routine was written that determines the maximum normal stress in the rake. Using the previously described properties for AL 7075-T6, the resulting maximum normal stress was calculated to be 9826 psi, giving a minimum FOS of 6.1 .

For transverse shear stress, a bolt spacing was calculated that would give a minimum FOS of at least 3 over yield strength and 4 over ultimate strength. A bolt size of \#6-32 was chosen for the bolts that connect the forward and rear arms together. The transverse shear stress was calculated to determine the spacing of bolts required to mount the forward arm to the rear arm of the rake.

The transverse shear stress in the rake arm is a maximum at the root and decreases to zero at the tip. Because of this, more bolts are required near the root. A simple numerical routine was created to facilitate the calculations.

To find the transverse shear stress, first the bolt spacing at the root is determined; the distance from the root to the first bolt must be equal to or less than this value. Then, where the first bolt is placed, the second bolt spacing is determined, and so on until the end of the arm is reached. The final bolt placement is shown in Table 3. As expected, the bolt spacing increases towards the tip as the transverse shear stress decreases.

This approach to determining the bolt spacing is very conservative because it assumes that the bolts are carrying all of the shear stress, when in reality the friction between the forward and rear arms along the mounting surface will transfer a portion of the shear stress through the fitting.

\section{Finite Element Calculation of Rake Stress}

Finally, SolidWorks ${ }^{\circledR}$ and COSMOSWorks ${ }^{\mathrm{TM}}$ (Dassault Systemes SolidWorks Corp., Concord, Massachussetts) were used to perform a finite element analysis of the rake. Because of symmetry, only one arm was modeled. A mesh was created using the integrated COSMOSWorks ${ }^{\mathrm{TM}}$ mesh tool with the default high-quality mesh option. The mesh had 95,672 nodes and 59,975 elements, and is shown in Fig. 8a. The boundary conditions are fixed on the symmetry plane as shown in Fig. $8 \mathrm{~b}$. The axial and normal forces are applied to the top and front surfaces as shown in Fig. 8c. Figure 8d shows contours of minimum FOS based on the yield strength of the material using the von Mises failure criterion. The maximum stress is 13,500 psi, which occurs at the root just behind the mid-chord point. Table 4 summarizes the stresses determined from both the standard stress calculations and computer analyses.

The overall minimum FOS was 4.4. This result is somewhat similar to the results obtained from the hand analysis even though the lower-order calculations used simplified geometry and boundary conditions. Stress risers at the bolt holes are likely the primary reason for the lower FOS.

\section{B. Probe Loads and Stress}

The probe geometry was analyzed using CFD to determine the loads acting on the probe structure. These loads were obtained by summing the forces and moments resulting from both pressure and viscous effects in the surrounding flowfield. They were then translated into shear and normal stress distributions acting within the probe structure. 


\section{Probe Computational Fluid Dynamics Loads Analysis}

The CFD flow solver used was the 3D Fully Unstructured Navier-Stokes (FUN3D) research code that is under continuing development by the NASA Langley Research Center (LaRC) in Hampton, Virginia. The analysis incorporated a steady-state, viscous model. The flight-test loads prediction case had a Reynolds number of order $10^{6}$, and as such the Spalart-Allmaras turbulence model ${ }^{8}$ was incorporated in order to capture any separation characteristics.

The flight condition used for the loading analysis was Mach 1.6 at an altitude of $20,000 \mathrm{ft}$ and $\alpha=20^{\circ}$. This is the highest expected dynamic pressure condition in flight, and includes a $2 \times$ factor on the maximum expected angle of attack in the wind tunnel or in flight. While the actual flight-test article will be flown at test points of $25,000 \mathrm{ft}$ altitude and $30,000 \mathrm{ft}$ altitude, wind-tunnel constraints prevented preliminary testing of the 30,000 ft altitude condition; as such $20,000 \mathrm{ft}$ and $25,000 \mathrm{ft}$ were used as test condition altitudes. Using a lower altitude than flight for the loads analysis provides an additional measure of conservatism in the estimate, as lower altitudes have higher atmospheric densities and thus higher dynamic pressure, which is the direct source of aerodynamic loading. The flight condition selected corresponds to a Reynolds number of $1.9764 \times 10^{6}$ (based on length).

\section{Experimental Validation of Probe Computational Fluid Dynamics}

The CFD model was validated by comparing the computed pitching-moment coefficient to experimental data obtained for a slender ogive cylinder in supersonic flow by Gudmundson and Torngren. ${ }^{9}$ The data are available in the form of moment coefficients as a function of angle of attack for several body shapes at Mach numbers of 1.42, 2.01, 2.51, and 3.08. The wind-tunnel stagnation (total) conditions were standard sea level pressure and temperature:

$$
\begin{aligned}
p_{t} & =2115 p s f \\
T_{t} & =518.4^{\circ} R
\end{aligned}
$$

Static pressures and temperatures to be simulated were determined using the stagnation values and the NACA tables for compressible flow, ${ }^{10}$ which are based on the isentropic relations. Because of their proximity to the desired flight-test condition the experimental data at Mach 1.42 and Mach 2.01 were used to validate the model. These Mach numbers bracket the primary flight-test condition of Mach 1.6, which is what was used for the CFD. In this case, stagnation values for the experimental data were different from those simulated, and the experimental model that was used is slightly different from the CFD model. The data validation CFD runs were set up to match the associated Reynolds number as well as the Mach number for the experimental data.

This is not strict dynamic similarity, which requires exact geometric similarity as a prerequisite, ${ }^{11}$ as the fineness ratios for the two models were different, a constant factor difference in the force coefficients was expected, as well as other geometry-dependent differences. Gudmundson and Torngren also do not include any wind-tunnel correction factors for blockage, et cetera, in their data. This was expected to cause additional minor discrepancies in the flow comparison. Despite these disparities, the moment and force coefficients were expected to follow similar trends and be of the same order of magnitude.

Figure 9 shows the validation CFD cases at Mach 1.6 and angle of attack values of $0^{\circ}, 2^{\circ}, 5^{\circ}$, and $10^{\circ}$. The experimental data at Mach 1.42 and Mach 2.01 have been divided by the ratio of the respective fineness ratios. From these plots the model was considered validated and loads determination could proceed.

\section{Probe Loads Analysis Results}

The reference geometry (in inches) was based on the wetted probe length, frontal cross-section, and diameter. Moments were taken about the root of the exposed section. These results are for Mach 1.6, an altitude of $20,000 \mathrm{ft}$, and $\alpha=20^{\circ}$.

The converged force and moment coefficients from FUN3D are provided in Table 5. The reference dimensions for these coefficients are a wetted area of $0.01131 \mathrm{in}^{2}$, a chord of 3.75 inches, and a span of 0.125 inches. These force and moment values are expected to be conservative, as they were computed at twice the planned wind-tunnel angle of attack $\left(20^{\circ}\right.$, as opposed to $\left.10^{\circ}\right)$. Note also that the comparison of viscous and pressure forces for the probes provides further justification for ignoring the viscous 
contribution on other components; the lift force contribution from viscous forces is four orders of magnitude less than the pressure contribution, two orders of magnitude for drag.

Using a numerical scripted procedure for calculating stress based on standard methods, the longitudinal loads and FOS were calculated to be:

$$
\begin{aligned}
& \sigma_{x x, \max }=9951 \mathrm{psi} \\
& \sigma_{\text {yield }}=25800 \mathrm{psi} \\
& F O S=2.5927
\end{aligned}
$$

This calculated FOS does not account for the additional measures of conservatism incorporated into the analysis as described previously. Thus the actual FOS is likely higher than this value.

\section{Rake, Boom, and Crayon Assembly Computational Fluid Dynamics}

In order to assess the stress distribution on the boom, which attaches the rake to the crayon, the total loads and moments were required. A 3D CFD analysis was performed on the rake and boom assembly in order to determine the aerodynamic loads on the structure in flight. Using exported CAD models, an unstructured mesh was created around a half-section of the rake-boom assembly, creating a symmetry plane normal to the lateral axis.

A worst-case flight condition, $\alpha=10^{\circ}$ at Mach 1.6 and an altitude of 30,000 ft, was used for the analysis. The inviscid Euler equations were used, as at such high Reynolds numbers (on the order of $10^{7}$ ) the ratio of viscous forces to inertial forces is quite small. The added computational expense of resolving the full 3D Navier-Stokes equations for such a large mesh was not deemed practical for the estimated small size of the viscous contribution.

The flow solver used was the Air Vehicles Unstructured Solver (AVUS) from the Air Force Research Laboratory, which is the internal government research version of the code that was commercialized to become COBALT. The grid was a 3D unstructured tetrahedron mesh with 3.36 million points and 17.8 million cells in 8 zones. The solver was set for a steady-state, inviscid computation at the predicted maximum dynamic pressure local condition of Mach 1.6 at an altitude of 30,000 ft. These PFTF-local conditions correspond to an aircraft flight condition of Mach 1.9 at an altitude of 40,000 ft.

The calculated loads and moments acting on the RAGE rake/boom assembly are shown in Fig. 10 and Fig. 11 as functions of local flow angle. Because the geometry of the RAGE structure is symmetric in the two axial planes, the flowfield response to angle of sideslip may be analyzed with the same flowfield as that for an equivalent angle of attack. The most restrictive operating limit for the experiment is a $500 \mathrm{lbf}$ side-force limit, resulting from the limits for the side-force strain gages present in the onboard PFTF force balance. This limit is reached at a relative wind angle of $1.75^{\circ}$. The product of sideslip angle and dynamic pressure is referred to as $\beta \mathrm{q}$ ("beta-q"). This quantity is directly proportional to the lateral load due to aerodynamic pressure forces. From the maximum expected value of dynamic pressure, the $\beta q$ limit corresponding to this angle is calculated to be 1967 psf-deg. Note that the moments in Figure 11 are not those in the CFD reference frame; they have been corrected to the load limit test reference frame, where the moment design limits for the PFTF have been defined from previous structural testing at DFRC.

Validation of the assembly CFD was completed in two ways. First, the curve of normal force coefficient versus relative wind angle was compared to previously-completed lower-order methods for the fixture - methods which were shown in earlier test flights to be more conservative than flight data. The comparison of the full 3D inviscid CFD to the lower-order methods is provided in Figure 12. The methods used for comparison were the compressible estimation developed by Saltzman as well as the Sin- $\beta$ method used by Saltzman and Vachon, both developed and/or used for F-15B Flight Test Fixture II (FTF-II) flights in previous projects. ${ }^{12}$ The latter method simply estimates the pressure force acting in the normal direction by multiplying the dynamic pressure by the sine of the relative wind angle to arrive at the normal component, then multiplying again by an estimate of the side profile equivalent flat-plate area. Obviously, neither method accounts for viscous effects, but at these Reynolds numbers there is arguably no need for such precision when only macroscopic quantities are being considered (for example, when the structure or behavior of the boundary layer is not of great concern).

Freestream $\beta q$ versus measured side load for past FTF-II research flights (in this case, LMI flights) is shown in Fig. 13, from which the conclusion can be drawn that the CFD and lower-order methods for this 
particular case are quite conservative, in fact almost excessively so. This wide margin is attributed to the fact that various significant flow-straightening features, such as the underbody of the F-15B, the PFTF itself, and the nearby engine inlets, are not modeled in any of the aerodynamic loads estimation methods. The high degree of conservatism will be retained for flight-planning purposes, however; the conservatism does not restrict or add expense to the flight-test program, and there is no quantitative reason to lower the safety margin.

\section{Boom Loads and Stress}

The loads from the rake/boom assembly CFD analysis were used in a SolidWorks ${ }^{\circledR}$ and COSMOSWorks ${ }^{\mathrm{TM}}$ stress analysis in order to verify that the boom design is strong enough for flighttesting. The boom has to have an FOS of 2.25 over ultimate strength to meet the NASA DFRC standard for hardware that has not undergone proof testing. The CFD analysis predicted a normal force of $131.1 \mathrm{lbf}$, an axial force of $49.3 \mathrm{lbf}$, and a pitching moment of $138.6 \mathrm{ft}-\mathrm{lbf}$ at the aft exposed end of the boom.

A solid model of the boom was created in SolidWorks ${ }^{\circledR}$. This model included all the mounting holes at the rear of the boom, but was simplified at the forward end where the internal moments and stress are small. A mesh was created with COSMOSWorks ${ }^{\mathrm{TM}}$. The mesh had 107,785 nodes and is shown in Fig. 14a.

The complex loading profile on the boom was simplified to a trapezoidal loading that would give the correct total force and overall moment for the rake and boom combination. This simplification was necessary in order to apply the forces to the SolidWorks ${ }^{\circledR}$ model. The boom is mounted to the fixture by way of two friction-fit sleeves that slide over the boom at approxmately 1 inch and 9 inches from the end; each sleeve has 1 bolt hole that attaches to the boom. The model was given fixed restraints at the bolt holes, and the cylindrical surfaces that the sleeves contact were restrained from moving in the radial direction.

Finally, the material (4130 steel) was applied and the analysis was run. The results showed that the minimum FOS was 15.3, giving a margin of safety of 13.05. A contour plot of FOS is shown in Fig. 14b. The maximum deformation, which occurs at the end of the boom, was 0.04372 inches. Figure $14 \mathrm{c}$ shows the deformation, exaggerated for visibility.

\section{System Calibration and Data Reduction}

The RAGE rake was calibrated in the Boeing Polysonic Wind Tunnel (PSWT) in St. Louis, Missouri. The raw data were sent through a developed calibration algorithm to arrive at fitted equation coefficients for use in real-time control room displays to monitor rake conditions in flight. The schematic of the probe and port numbering convention for the wind-tunnel test and calibration section remains as shown in Fig. 4.

\section{A. Wind-tunnel Test}

The PSWT is a $4 \mathrm{ft}$ by $4 \mathrm{ft}$ blowdown tunnel capable of operating in subsonic through hypersonic speeds. The rake was tested at three different Mach numbers: $\mathrm{M}=1.461,1.508$, and 1.611, at Reynolds numbers of 6.2, 6.7, and 6.85 million per foot respectively. An additional test was performed at $\mathrm{M}=1.508$ and Reynolds number of 5.7 million per foot to determine any Reynolds number effects on the calibration. Literature on conical probes suggested that Reynolds number effects are negligible at the Mach numbers being tested. ${ }^{14}$

The 45 probe pressures were measured with a single 48-port 2160-psf ESP module. The uncertainty for any single port is $1.3 \mathrm{psf}$. Wind-tunnel static pressure, total pressure, and total temperature were measured, and Mach number was calculated with an uncertainty of 0.015 Mach. Pitch and roll were measured with potentiometers with uncertainties of $0.013 \mathrm{deg}$ and $0.07 \mathrm{deg}$, respectively.

The rake was attached to a roll-pod and sting that could be rotated in roll and pitch. Various combinations of the two axes were rotated in order to position the rake at angles of attack and sideslip from $-10^{\circ}$ to $10^{\circ}$ in increments of $2.5^{\circ}$. The pitch axis of rotation was positioned at the center probe tip as shown in Fig. 15. A total of 82 calibration points were taken at each Mach number. One inverted zero-pitch test point was included at each Mach number in order quantify tunnel flow angularity and model misalignment.

A comparison of the calibration data showed no significant differences between the nine probes. In addition, the data obtained from the two runs at $\mathrm{M}=1.508$ showed no significant Reynolds number effects. As a result, only the calibration results for the center probe (probe 1) are presented in this paper. 


\section{B. Probe Misalignment Correction}

The rake was positioned in the wind tunnel in an effort to align the probes parallel to the upper and lower wind-tunnel walls; however, rake mounting errors, tunnel flowstream angularity, and probe geometric asymmetry from machining tolerances result in the probes not being aligned with the flow at zero angle of attack and angle of sideslip. In general, the probes will be offset from the local velocity vector by small vertical $\left(\theta_{0}\right)$ and horizontal $\left(\delta_{0}\right)$ angles. In order to determine these angles, the tips of the probes must remain stationary at a fixed point in the tunnel. This restriction comes about due to small variations in stream angularity from point to point in the tunnel.

For the experiment, the probe and port numbering conventions were consistent with those shown in Fig. 4. In this experiment, the axis of rotation of the rake was located at the tip of the center probe; therefore, the tip of the center probe remained fixed in the tunnel as the rake was pitched and rolled, whereas the tips of probes 2-9 necessarily changed location in the tunnel because of the geometry of the rake. As a result, the data from probe 1 were used to compute the misalignment correction. The inability to determine the individual misalignment angles of probes 2-9 is of no consequence, since it is desired to know the flow angularity at these probes with respect to the centerline axis of the rake, which fortuitously coincides with the centerline axis of probe 1 .

In order to determine $\theta_{0}$, a vertical pressure coefficient $\left(\mathrm{C}_{\theta}\right)$ was defined as the pressure difference between the static pressure ports 3 and $5\left(\mathrm{p}_{3}\right.$ and $\left.\mathrm{p}_{5}\right)$, normalized by the tunnel dynamic pressure $(\mathrm{q})$, see Eq. (3).

$$
C_{\theta}=\frac{p_{3}-p_{5}}{q}
$$

When the rake is set at $\phi=0^{\circ},-180^{\circ}, \mathrm{p}_{3}$ and $\mathrm{p}_{5}$ lie in the plane of rotation; consequently, the pressure difference between these ports will be maximum and $\mathrm{C}_{\theta}$ will vary linearly with pitch angle. Experimental data for probe 1, presented in Figs. 16-18, show $\mathrm{C}_{\theta}$ as a function of pitch angle at a roll angle of $\phi=-180^{\circ}$. The data in each figure were fit with linear curves so that the point of intersection could be determined. The intersection of these curves corresponds to the pitch angle where $\mathrm{C}_{\theta}$ is independent of $\phi$, meaning that the probe is aligned with the local velocity vector. ${ }^{13}$ The ordinate and abscissa values at the intersection point yield the vertical bias angle $\theta_{0}$, and the pitch coefficient offset $C_{\theta, 0}$ due to the geometric asymmetry of the probe tip. The vertical offset angles for probe 1 at the three calibration Mach numbers $\mathrm{M}=1.461,1.508$, 1.611 were determined to be $\theta_{0}=-0.56^{\circ},-0.42^{\circ}$, and $-0.15^{\circ}$, respectively.

The horizontal misalignment angle $\delta_{0}$ couldn't be determined because the rake was only pitched in the vertical direction. As a result, the horizontal bias angle was set equal to zero. Any horizontal misalignment due to mounting inaccuracies would necessarily be small because the tunnel sting cannot be rotated in the horizontal plane.

A corrected pitch angle $\left(\theta_{\mathrm{n}}\right)$ and roll angle $\left(\phi_{\mathrm{n}}\right)$ were defined to account for the vertical misalignment errors. In general, a series of four coordinate transformations is necessary to solve for $\theta_{\mathrm{n}}$ and $\phi_{\mathrm{n}} ;{ }^{13}$ however, since it was assumed that $\delta_{0}=0$, the corrected roll angle $\phi_{\mathrm{n}}=\phi$, thus making the coordinate transformations unnecessary. The corrected pitch angle $\theta_{\mathrm{n}}$ was calculated by subtracting the vertical bias angle $\theta_{0}$ from the wind-tunnel-measured pitch angle $\theta$. The local angles $\alpha$ and $\beta$ were recomputed using the $\theta_{\mathrm{n}}, \phi_{\mathrm{n}}$, and the relations presented in Eqs. (4) and (5):

$$
\begin{aligned}
& \alpha=\tan ^{-1}\left[\tan \theta_{n} \cos \phi_{n}\right] \\
& \beta=\tan ^{-1}\left[\tan \theta_{\mathrm{n}} \sin \phi_{\mathrm{n}}\right] .
\end{aligned}
$$

\section{Mach Number Determination}

The local Mach number $\left(\mathrm{M}_{\text {local }}\right)$ for each probe is calculated through an iterative algorithm, starting with an initial guess $\left(\mathrm{M}_{1}\right)$ and then repeating the calculation procedure until the output Mach number is within some tolerance of the last iteration's estimate. The local Mach number is a function of the ratio of the arithmetic mean of the four static pressures to the pitot pressure $\left(\mathrm{p}_{\mathrm{a}} / \mathrm{p}_{\mathrm{t} 2}\right)$, and the probe inclination to the 
local flowfield. If the probe is aligned with the local velocity vector, the Mach number can be determined directly from $\mathrm{p}_{\mathrm{a}} / \mathrm{p}_{\mathrm{t} 2}$. Experimental results for probe 1 at $\theta=0^{\circ}$ are shown in Fig. 19. It is observed that the ratio of static pressure to pitot pressure decreases with increasing Mach number. For comparison, the theoretical static pressure distribution for a cone of $60^{\circ}$ semi-apex angle in axial flow is plotted along with the experimental data. The experimental values of $\mathrm{p}_{\mathrm{a}} / \mathrm{p}_{\mathrm{t} 2}$ are slightly higher than the theory, but match the overall trend. The reason for this difference can be attributed to the existence of the pitot port on the tip of the cone as compared to a sharp tip for the theoretical solution.

Data from Refs. 14 and 15 show that $\mathrm{p}_{\mathrm{a}} / \mathrm{p}_{\mathrm{t} 2}$ for conical probes varies with pitch inclination at a given supersonic Mach number. Experimental data showing the change in $\mathrm{p}_{\mathrm{a}} / \mathrm{p}_{\mathrm{t} 2}$ as a function of $\theta_{\mathrm{n}}$ over a representative range of $\phi_{\mathrm{n}}$ are shown in Figs. 20a-20d. Data were taken at 21 different values of $\phi_{\mathrm{n}}$; however, only four plots are shown in this figure in the interest of brevity. These four plots were chosen because they are representative of the overall data trend for all $\phi_{\mathrm{n}}$. It is necessary to note that the data points at positive values of $\theta_{\mathrm{n}}$ for $\phi_{\mathrm{n}}=0^{\circ}, 180^{\circ}$ were mirrored from the measured values at negative $\theta_{\mathrm{n}}$, since calibration data weren't taken at positive $\theta_{\mathrm{n}}$ at these two $\phi_{\mathrm{n}}$.

The curves for all 21 distinct values of $\phi_{\mathrm{n}}$ were combined to create a $3 \mathrm{D}$ calibration map of $\left(\mathrm{p}_{\mathrm{a}} / \mathrm{p}_{\mathrm{t} 2}\right)_{\theta} /$ $\left(\mathrm{p}_{\mathrm{a}} / \mathrm{p}_{\mathrm{t} 2}\right)_{\theta=0}$ as a function of $\theta_{\mathrm{n}}$ and $\phi_{\mathrm{n}}$. Since the range of pitch angles in which wind-tunnel data were taken was different for 19 of the 21 roll angles tested, it was necessary to extrapolate the remaining 19 curves out to a common max/min value of $\theta_{\mathrm{n}}$. The largest pitch angles where calibration data were taken were at roll angles of $\phi_{\mathrm{n}}=-135^{\circ},-45^{\circ}$. As a result, the values of $\left(\mathrm{p}_{\mathrm{a}} / \mathrm{p}_{\mathrm{t} 2}\right)_{\theta} /\left(\mathrm{p}_{\mathrm{a}} / \mathrm{p}_{\mathrm{t} 2}\right)_{\theta=0}$ at $\theta_{\mathrm{n}}=\theta_{\mathrm{n}}(\mathrm{max} / \mathrm{min})$ for these two roll angles were used to extrapolate the other 19 curves out to a common range of $\theta_{\mathrm{n}}$. The data points from the 21 extrapolated curves were used to interpolate a surface map of calibration data. The resulting $3 \mathrm{D}$ calibration maps for all three Mach numbers are shown in Figs. 21a-21c.

Data found in Ref. 16 show that pitot tubes have a range of insensitivity to flow inclination that is dependent upon the shape of the probe. This range of insensitivity is typically defined using a limit of $1 \%$ total pressure loss. Figure 22 shows a plot of the pitot-to-freestream total pressure ratio $\mathrm{p}_{\mathrm{t} 2} / \mathrm{p}_{\mathrm{t} 1}$ as a function of $\theta_{\mathrm{n}}$. The pitot pressure is constant up to approximately $\theta_{\mathrm{n}}= \pm 11^{\circ}$, beyond which it begins to decrease slightly. It can be seen by looking at the $\mathrm{M}=1.461$ curve in Fig. 22 that $\mathrm{p}_{\mathrm{t} 2}$ has dropped by only $0.45 \%$ at the maximum pitch angle $\theta_{\mathrm{n}}=14.6^{\circ}$, signifying that $\mathrm{p}_{\mathrm{t} 2}$, unlike $\mathrm{p}_{\mathrm{a}}$, is effectively insensitive to flow inclination over the entire range of $\theta_{\mathrm{n}}$ tested.

To compute the local Mach number, $\mathrm{p}_{\mathrm{a}}$ and $\mathrm{p}_{\mathrm{a}} / \mathrm{p}_{\mathrm{t} 2}$ are calculated based on the measured probe pressures. The computed value of $\mathrm{p}_{\mathrm{a}} / \mathrm{p}_{\mathrm{t} 2}$ is used along with Fig. 19 to derive an estimate of the local Mach number. Normal shock and isentropic relations are then used to solve for the total and dynamic pressures. The local flow angles are computed, and $\theta_{\mathrm{n}}$ and $\phi_{\mathrm{n}}$ are used with Fig. 21 to obtain an estimate for $\mathrm{p}_{\mathrm{a}} / \mathrm{p}_{\mathrm{t} 2}$ at zero-flow inclination. The corrected value of $\mathrm{p}_{\mathrm{a}} / \mathrm{p}_{\mathrm{t} 2}$ at zero-flow inclination and Fig. 19 are used to derive a better approximation of the local Mach number.

\section{Flow Angularity Determination}

The flow angles are determined using the measured pressures across pairs of opposing static pressure ports. Angle of attack and body axis angle of sideslip pressure coefficients are defined as shown in Eqs. (6) and (7):

$$
\begin{gathered}
C p_{\alpha}=\frac{p_{3}-p_{5}}{q} \\
C p_{\beta}=\frac{p_{4}-p_{2}}{q}
\end{gathered}
$$

Figure 23 shows the results for $\mathrm{Cp}_{\alpha}$ plotted versus $\mathrm{Cp}_{\beta}$. The data exhibit a small dependency on Mach number at the larger flow angles. Each data point shown in Fig. 21 has a corresponding value of $\alpha$ and $\beta$ associated with it. This permitted the construction of calibration surface maps where $\alpha, \beta=\mathrm{f}\left(\mathrm{Cp}_{\alpha}, \mathrm{Cp}_{\beta}\right)$. The resultant maps are shown in Figs. 24a-24f. To determine the flow angularity, the dynamic pressure is calculated, as mentioned in the previous section, and $\mathrm{Cp}_{\alpha}$ and $\mathrm{Cp}_{\beta}$ are obtained from the definitions given above. The computed $\mathrm{Cp}_{\alpha}$ and $\mathrm{Cp}_{\beta}$ are then used with Fig. 24 to determine $\alpha$ and $\beta$. 


\section{E. Solution Algorithm}

The computation of the local Mach number, angle of attack, and angle of sideslip follows the method given in Ref. 14. The following example describes the steps used in the computation of these quantities. First, the measured port pressures are used to calculate $\mathrm{p}_{\mathrm{a}}$ and $\mathrm{p}_{\mathrm{a}} / \mathrm{p}_{\mathrm{t} 2}$, as shown in Eq. (8):

$$
p_{a}=\frac{1}{4}\left(p_{2}+p_{3}+p_{4}+p_{5}\right)
$$

Since the pitch angle is initially unknown, it is first assumed that $\theta_{\mathrm{n}}=0$. An initial estimate of Mach number $\left(\mathrm{M}_{1}\right)$ is then obtained from Fig. 18 using $\mathrm{p}_{\mathrm{a}} / \mathrm{p}_{\mathrm{t} 2}$. The total pressure is calculated from normal shock relations as given in Eq. (9):

$$
\frac{p_{t_{2}}}{p_{t_{1}}}=\left(\frac{6 M_{1}^{2}}{M_{1}^{2}+5}\right)^{(7 / 2)}\left(\frac{6}{7 M_{1}^{2}-1}\right)^{(5 / 2)}
$$

The dynamic pressure of the flow ahead of the shock is obtained using the isentropic flow relation, shown in Eq. (10):

$$
\frac{q}{p_{t_{1}}}=\left(\frac{7 M_{1}^{2}}{10}\right)\left(1+\frac{M_{1}^{2}}{5}\right)^{(-7 / 2)}
$$

and the flow angularity pressure coefficients $\mathrm{Cp}_{\alpha}$ and $\mathrm{Cp}_{\beta}$ are calculated using the measured static pressures shown in Eqs. (11) and (12):

$$
\begin{aligned}
C p_{\alpha} & =\frac{p_{3}-p_{5}}{q} \\
C p_{\beta} & =\frac{p_{4}-p_{2}}{q}
\end{aligned}
$$

Once $\mathrm{Cp}_{\alpha}$ and $\mathrm{Cp}_{\beta}$ are known, $\alpha$ and $\beta$ are determined from the calibration maps shown in Fig. 24. The pitch and roll angles $\theta_{\mathrm{n}}$ and $\phi_{\mathrm{n}}$ are related to $\alpha$ and $\beta$ as shown in Eq. (13):

$$
\theta_{n}= \pm \tan ^{-1}\left[\tan ^{2} \alpha+\tan ^{2} \beta\right]^{1 / 2}
$$

and in Eq. (14):

$$
\phi_{n}=\cos ^{-1}\left[\frac{\tan \alpha}{\tan \theta_{n}}\right]
$$

For the purposes of this experiment, $\theta_{\mathrm{n}}$ is positive when $\beta_{\mathrm{b}}$ (body axis angle of sideslip) is negative, and negative when $\beta_{\mathrm{b}}$ is positive. Furthermore, $\phi_{\mathrm{n}}$ is multiplied by -1 , due to the fact that the wind-tunnel calibration data were obtained using negative values of $\phi_{\mathrm{n}}$ only. If necessary, the pitot pressure is corrected for flow angle effects using $\theta_{\mathrm{n}}$ and Fig. 22. The corrected value of pitot pressure at $\theta_{\mathrm{n}}=0$ is obtained as shown in Eq. (15): 


$$
\left(p_{t_{2}}\right)_{\theta_{n}=0}=\frac{p_{t_{2}}}{\left(\frac{p_{t_{2}}}{p_{t 1}}\right)_{\theta_{n}} /\left(\frac{p_{t_{2}}}{p_{t 1}}\right)_{\theta_{n}=0}}
$$

Typically, the flow will not be aligned with the local velocity vector, so $\mathrm{p}_{\mathrm{a}} / \mathrm{p}_{\mathrm{t} 2}$ must be corrected for flow angularity. The computed probe angles are used with Fig. 21 to obtain a correction factor for $\mathrm{p}_{\mathrm{a}} / \mathrm{p}_{\mathrm{t} 2}$. The ratio of static to pitot pressures at $\theta_{\mathrm{n}}=0$ is then determined from the relation shown in Eq. (16):

$$
\left(\frac{p_{a}}{p_{t_{2}}}\right)_{\theta_{n}=0}=\frac{\left(\frac{p_{a}}{p_{t_{2}}}\right)_{\theta_{n}}}{\left(\frac{p_{a}}{p_{t_{2}}}\right)_{\theta_{n}} /\left(\frac{p_{a}}{p_{t_{2}}}\right)_{\theta_{n}=0}}
$$

A second approximation of the local Mach number is obtained using the corrected $\mathrm{p}_{\mathrm{a}} / \mathrm{p}_{\mathrm{t} 2}$, and the process is repeated until the desired accuracy is achieved. For this experiment, the body axis angle of sideslip was converted to the true angle of sideslip $\left(\beta_{t}\right)$ as shown in Eq. (17):

$$
\beta_{t}=\tan ^{-1}[\tan \beta \cos \alpha]
$$

The above algorithm was numerically coded, and the calibration maps were stored as lookup tables for use with pressures measured in flight. During research flights, there will necessarily be times that the probe local Mach number will not be equal to any of the three calibration Mach numbers. This raises the question of which calibration Mach number to use for the lookup tables. A simple approach would be to use the calibration Mach number that is closest to the initial estimate $\mathrm{M}_{1}$ obtained from Fig. 19.

A more accurate method would be to interpolate a solution at $\mathrm{M}_{1}$ using solutions obtained from the two calibration Mach numbers that bracket $\mathrm{M}_{1}$. The latter of the two methods was coded numerically and works as demonstrated in the following example. If the initial estimate $\mathrm{M}_{1}=1.48$, one iteration of the algorithm is performed using the lookup tables based on the $\mathrm{M}=1.461$ calibration data. A second iteration is also performed using the $\mathrm{M}=1.508$ calibration data. One then linearly interpolates between the two bracketing solutions to arrive at a solution for $\mathrm{M}_{\text {local }}$ based on $\mathrm{M}_{1}=1.48$. This process is repeated using the the calculated value of $\mathrm{M}_{\text {local }}$ as the starting point for the next iteration until the change in $\mathrm{M}_{\text {local }}$ from one iteration to the next is less than some convergence limit. The estimated uncertainties using this method with the data obtained during the wind-tunnel calibration are given in Table 6.

\section{Concluding Remarks}

In order to maximize the utility of the Propulsion Flight Test Fixture (PFTF), the flow angularity and Mach number must be known at a nominal PFTF test article interface plane; this was accomplished with the Rake Airflow Gauge Experiment (RAGE). The RAGE test article, consisting of nine five-hole conical probes, has been designed and calibrated. The design called for a minimum factor of safety of 2.25 and the analysis showed that all the margins are positive. The design process included aerodynamic loads estimation, consideration of the structural response, and the development of a wind-tunnel calibration algorithm.

The calibration was completed at the The Boeing Company (St. Louis, Missouri) Polysonic Wind Tunnel and yielded calibration factors for testing angles of attack and sideslip in the range of $-10^{\circ}$ to $10^{\circ}$, and at Mach numbers ranging from 1.4 to 1.6. The vertical misalignment and other relevant data-calibration 
parameters were successfully calculated, and, based on the information gathered from the calibration process, a real-time algorithm for determining the local Mach number and the flow angle during flight was developed. It is intended that the design, analysis, testing, and calibration process described in this paper may be of use to future researchers interested in constructing similar instrumentation structures or related hardware.

In late calendar year 2008, the RAGE will be flown on the PFTF, which will greatly increase the usefulness of the system for future flight-test projects including the Channeled Centerbody Inlet Experiment, a subject of future research that will utilize the platform. These flight tests will corroborate the design and analysis work intended to make the PFTF a versatile and powerful tool for future experiments by the aerospace community on this platform.

\section{References}

${ }^{1}$ Corda, S., et al., "The F-15B Propulsion Flight Test Fixture: A New Flight Facility For Propulsion Research,"NASA/TM-2001-210395, 2001.

${ }^{2}$ Vachon, M. J., Moes, T. R., and Corda, S., "Local Flow Conditions for Propulsion Experiments on the F-15B Propulsion Flight Test Fixture,” NASA/TM-2005-213670, 2005.

${ }^{3}$ Palumbo, N., Moes, T., Vachon, M. J., "Initial Flight Tests of the NASA F-15B Propulsion Flight Test Fixture" AIAA-2002-4131, 2002.

${ }^{4}$ Weir, L. J., Sanders, B. W., and Vachon, J., “A New Design Concept for Supersonic Axisymmetric Inlets," AIAA-2002-3775, 2002.

${ }^{5}$ Hilton, J. H., Jr., "Flow Characteristics Over a Lifting Wedge of Finite Aspect Ratio with Attached and Detached Shock Waves at a Mach Number of 1.4," NACA Technical Note 2712, 1952.

${ }^{6}$ Aeronautical Systems Center, Department of Defense, Metallic Materials and Elements for Aerospace Vehicle Structures, MIL-HDBK-5J, 2003.

${ }^{7}$ Budynas, R. G., Advanced Strength and Applied Stress Analysis, $2^{\text {nd }}$ ed., McGraw-Hill, 1999.

${ }^{8}$ Spalart, P. R., and Allmaras, S. R., "A One-Equation Turbulence Model for Aerodynamic Flows," AIAA-92-0439, 1992.

${ }^{9}$ Gudmundson, S. E., and Torngren, L., "Supersonic and Transonic Wind Tunnel Tests on a Slender Ogivecylinder Body Single and in Combination with Cruciform Wings and Tails of Different Sizes," Aeronautical Research Institute of Sweden, FF-AU-772, 1972.

${ }^{10}$ Ames Research Staff, "Equations, Tables, and Charts for Compressible Flow," NACA Report 1135, Ames Aeronautical Laboratory, 1953.

${ }^{11}$ White, F. M., Fluid Mechanics, $5^{\text {th }}$ ed., McGraw-Hill, 2002.

${ }^{12}$ FTF-II Project Team, "FTF-II Structural Critical Design Review," internal presentation, NASA Dryden Flight Research Center, March 2000.

${ }^{13}$ Centolanzi, F. J., "Characteristics of a $40^{\circ}$ Cone for Measuring Mach Number, Total Pressure, and Flow Angles at Supersonic Speeds," NACA Technical Note 3967, 1957.

${ }^{14}$ Zeiger, M. D., and Shaeffler, N. W., "Correcting Multi-Hole Probe Alignment Bias Errors PostCalibration," AIAA-2001-900, 2001.

${ }^{15}$ Andrews, D. R., and Sawyer, W. G., "The Calibration of a $60^{\circ}$ Cone to Measure Mach Number, Total Pressure, and Flow Angles at Supersonic Speeds," Ministry of Aviation, Aeronautical Research Council, 1963.

${ }^{16}$ Gracey, W., "Measurement of Aircraft Speed and Altitude,” NASA RP-1046, 1980. 
Table 1. Comparison of computational fluid dynamics results to NACA-based

calculations for rake loads.

\begin{tabular}{|l|l|l|l|}
\hline Quantity & CFD & NACA & $\%$ diff \\
\hline $\mathrm{F}_{\mathrm{n}} / 1$ & $328 \mathrm{lb} / \mathrm{ft}$ & $255 \mathrm{lb} / \mathrm{ft}$ & $22 \%$ \\
\hline $\mathrm{F}_{\mathrm{t}} / 1$ & $33 \mathrm{lb} / \mathrm{ft}$ & $13 \mathrm{lb} / \mathrm{ft}$ & $60 \%$ \\
\hline $\mathrm{M} / 1$ & $28 \mathrm{lb}$ & na & na \\
\hline c.p. & $41 \%$ & $45 \%$ & $8.8 \%$ \\
\hline
\end{tabular}

Table 2. Material properties for 7075-T6 Aluminum.

\begin{tabular}{|l|l|l|}
\hline Material & E, ksi & $\mathrm{F}_{\text {t,yield }}$, ksi \\
\hline AL 7075-T6 & 10,300 & 60.2
\end{tabular}

Table 3. Bolt placement.

\begin{tabular}{|c|c|}
\hline Bolt number & Distance from root, in. \\
\hline 1 & .5 \\
\hline 2 & 1 \\
\hline 3 & 1.5 \\
\hline 4 & 2 \\
\hline 5 & 2.75 \\
\hline 6 & 3.5 \\
\hline 7 & 4.25 \\
\hline
\end{tabular}

Table 4. Summary of maximum rake stress and minimum factor of safety calculations.

\begin{tabular}{|c|c|c|}
\hline & $\sigma_{\mathrm{n}, \max }, \mathrm{psi}$ & $\mathrm{FOS}_{\min }$ \\
\hline $\begin{array}{c}\text { Analytical } \\
\text { methods }\end{array}$ & 9826 & 6.1 \\
\hline $\begin{array}{c}\text { Finite element } \\
\text { analysis }\end{array}$ & 13500 & 4.4 \\
\hline
\end{tabular}


Table 5. Force coefficient tabulation for Rake Airflow Gauge Experiment probe viscous computational fluid dynamics, pressure altitude $20,000 \mathrm{ft}$ at Mach 1.6.

\begin{tabular}{|l|l|l|}
\hline PRESSURE FORCES: & & \\
\hline$C_{L}=0.1407315 \mathrm{E}+01$ & $\mathrm{C}_{\mathrm{D}}=0.7229944 \mathrm{E}+00$ & \\
\hline $\mathrm{C}_{\mathrm{l}}=-0.4406300 \mathrm{E}-05$ & $\mathrm{C}_{\mathrm{m}}=0.8593886 \mathrm{E}+00$ & $\mathrm{C}_{\mathrm{n}}=-0.1022608 \mathrm{E}+00$ \\
\hline $\mathrm{C}_{\mathrm{X}}=0.1980623 \mathrm{E}+00$ & $\mathrm{C}_{\mathrm{Y}}=0.1255074 \mathrm{E}-02$ & $\mathrm{C}_{\mathrm{Z}}=0.1569723 \mathrm{E}+01$ \\
\hline & & \\
\hline VISCOUS FORCES: & & \\
\hline $\mathrm{C}_{\mathrm{L}}=-0.1999097 \mathrm{E}-03$ & $\mathrm{C}_{\mathrm{D}}=0.3835171 \mathrm{E}-02$ & $\mathrm{C}_{\mathrm{n}}=0.7427567 \mathrm{E}-04$ \\
\hline $\mathrm{Cl}=-0.3198020 \mathrm{E}-05$ & $\mathrm{C}_{\mathrm{m}}=0.5841135 \mathrm{E}-03$ & $\mathrm{C}_{\mathrm{Z}}=0.1123852 \mathrm{E}-02$ \\
\hline $\mathrm{C}_{\mathrm{X}}=0.3672255 \mathrm{E}-02$ & $\mathrm{C}_{\mathrm{Y}}=-0.6568317 \mathrm{E}-05$ & \\
\hline & & \\
\hline $\mathrm{TOT}_{\mathrm{N}} \mathrm{FORCES}:$ & & $\mathrm{C}_{\mathrm{n}}=-0.1021865 \mathrm{E}+00$ \\
\hline $\mathrm{C}_{\mathrm{L}}=0.1407116 \mathrm{E}+01$ & $\mathrm{C}_{\mathrm{D}}=0.7268296 \mathrm{E}+00$ & $\mathrm{C}_{\mathrm{Z}}=0.1570846 \mathrm{E}+01$ \\
\hline $\mathrm{C}_{\mathrm{l}}=-0.7604320 \mathrm{E}-05$ & $\mathrm{C}_{\mathrm{Y}}=0.1248505 \mathrm{E}-02$ & \\
\hline $\mathrm{C}_{\mathrm{X}}=0.2017346 \mathrm{E}+00$ & & \\
\hline
\end{tabular}

Table 6. Estimated uncertainties for wind-tunnel calibration.

\begin{tabular}{|c|c|c|c|c|c|c|}
\hline & \multicolumn{2}{|c|}{$\mathrm{M}_{\infty}=1.461$} & \multicolumn{2}{c|}{$\mathrm{M}_{\infty}=1.508$} & \multicolumn{2}{c|}{$\mathrm{M}_{\infty}=1.611$} \\
\cline { 2 - 7 } & $\alpha, \beta_{\mathrm{t}}=0^{\circ}$ & $\alpha, \beta_{\mathrm{t}}=10^{\circ}$ & $\alpha, \beta_{\mathrm{t}}=0^{\circ}$ & $\alpha, \beta_{\mathrm{t}}=10^{\circ}$ & $\alpha, \beta_{\mathrm{t}}=0^{\circ}$ & $\alpha, \beta_{\mathrm{t}}=10^{\circ}$ \\
\hline $\mathrm{M}_{\text {local }}$ & \pm 0.02 & \pm 0.065 & \pm 0.02 & \pm 0.065 & \pm 0.02 & \pm 0.065 \\
\hline$\alpha$ & $\pm 0.25^{\circ}$ & \pm 0.75 & $\pm 0.25^{\circ}$ & \pm 0.75 & $\pm 0.25^{\circ}$ & \pm 0.75 \\
\hline$\beta_{\mathrm{t}}$ & $\pm 0.25^{\circ}$ & \pm 0.75 & $\pm 0.25^{\circ}$ & \pm 0.75 & $\pm 0.25^{\circ}$ & \pm 0.75 \\
\hline
\end{tabular}




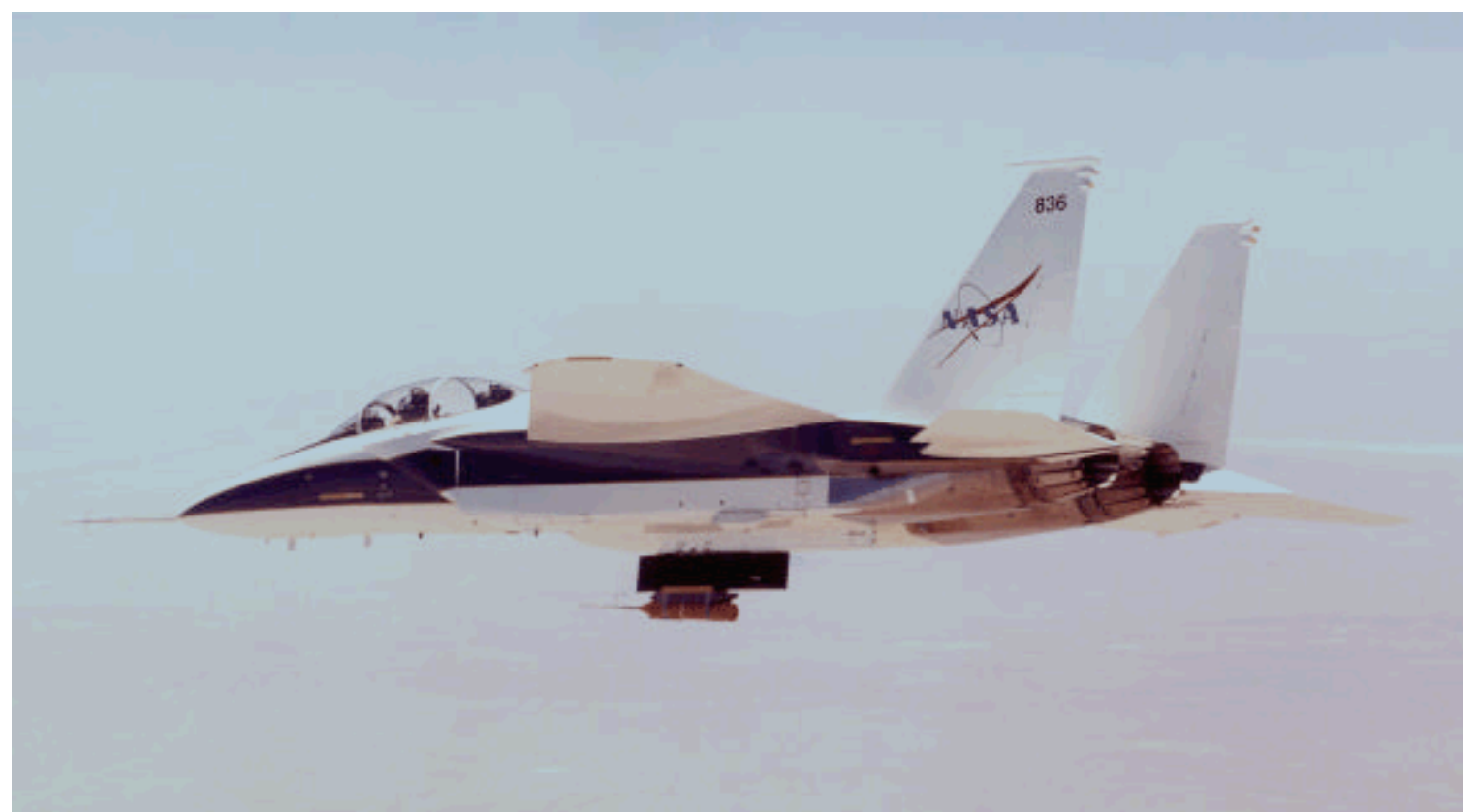

Figure 1. One of the NASA Dryden Flight Research Center F-15B aircraft, tail number 836, shown in flight with the Propulsion Flight-test Fixture pylon. 


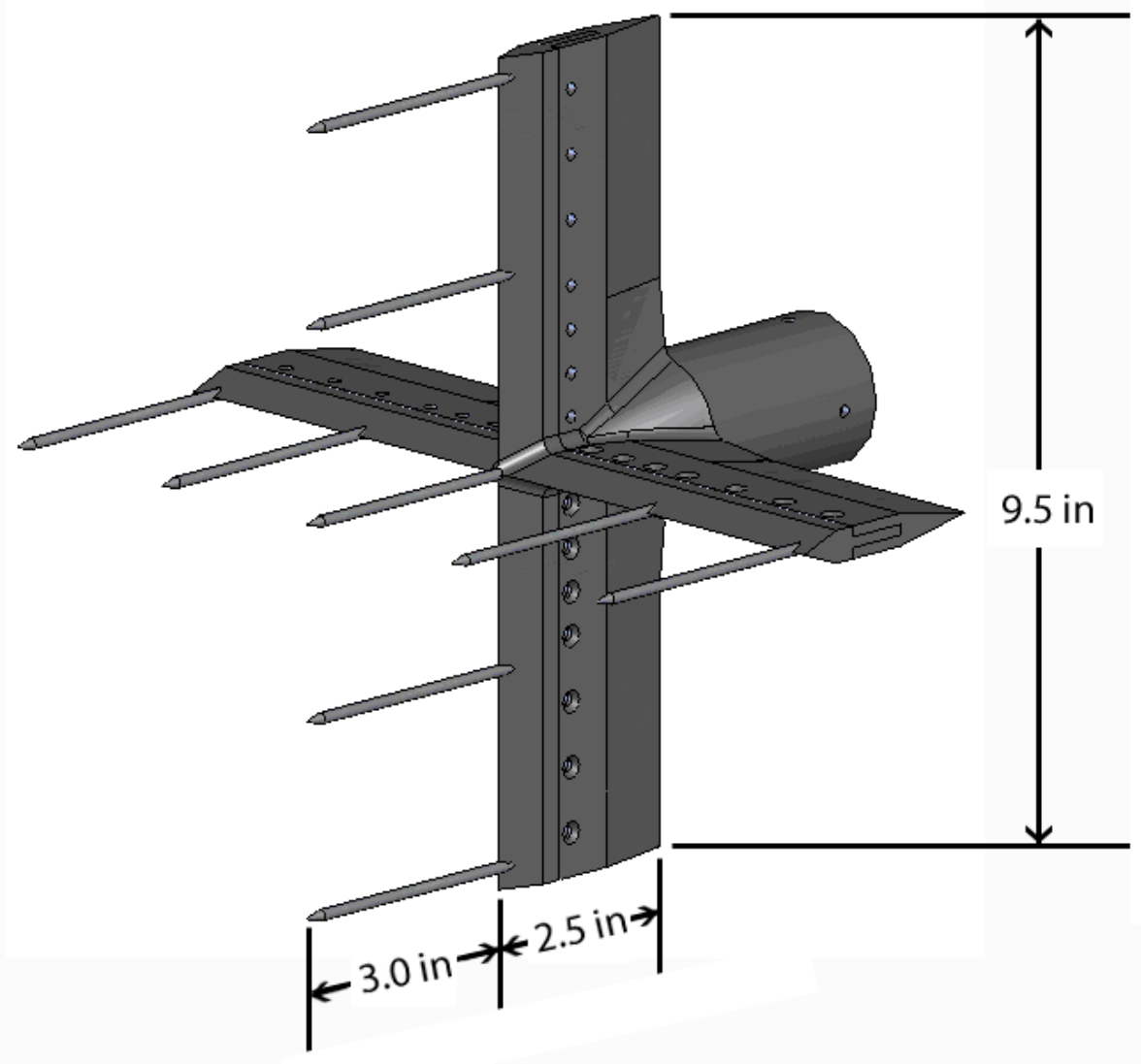

Figure 2. The flowfield rake with probes. 


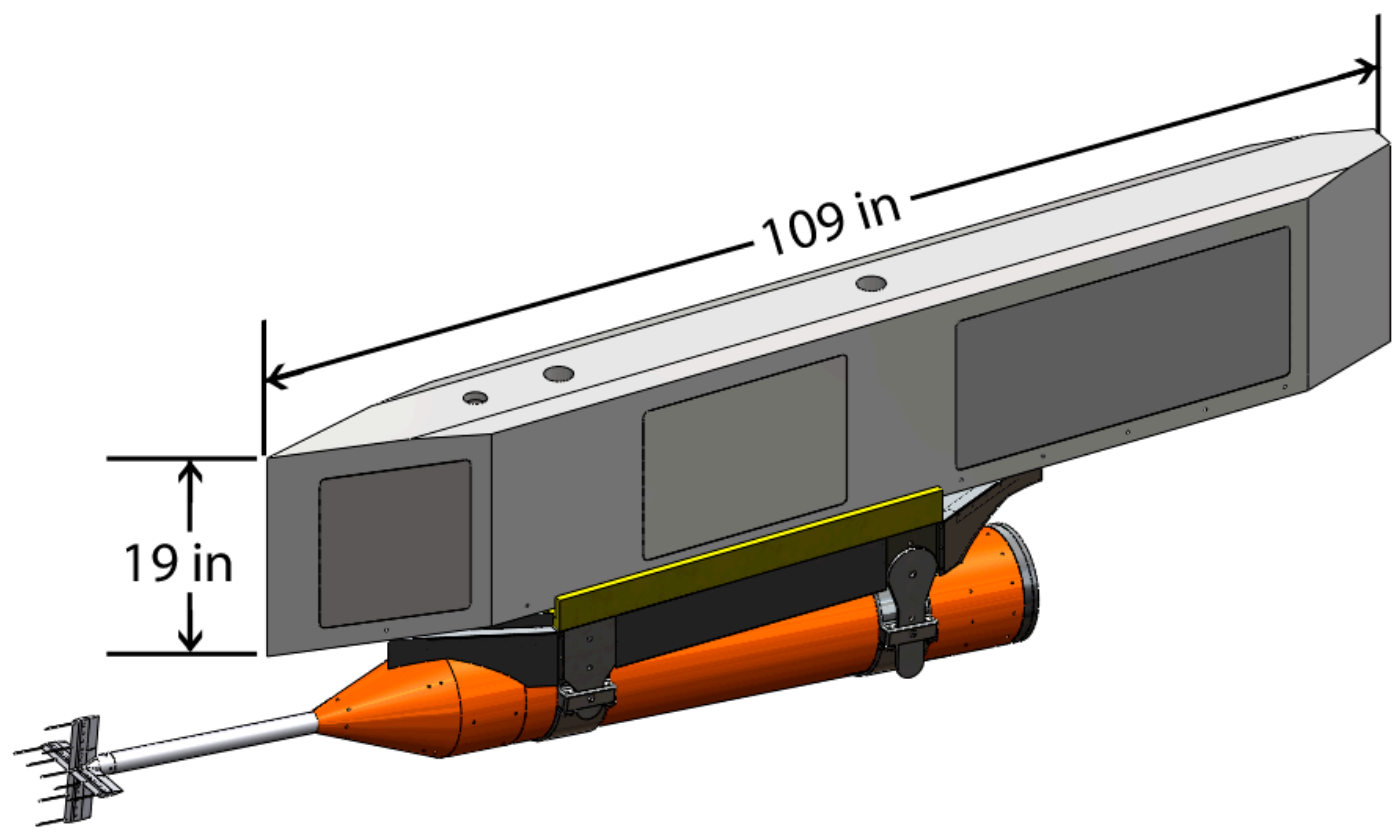

Figure 3. The Propulsion Flight Test Fixture with the flowfield rake, Local Mach Investigation boom, and crayon attached.

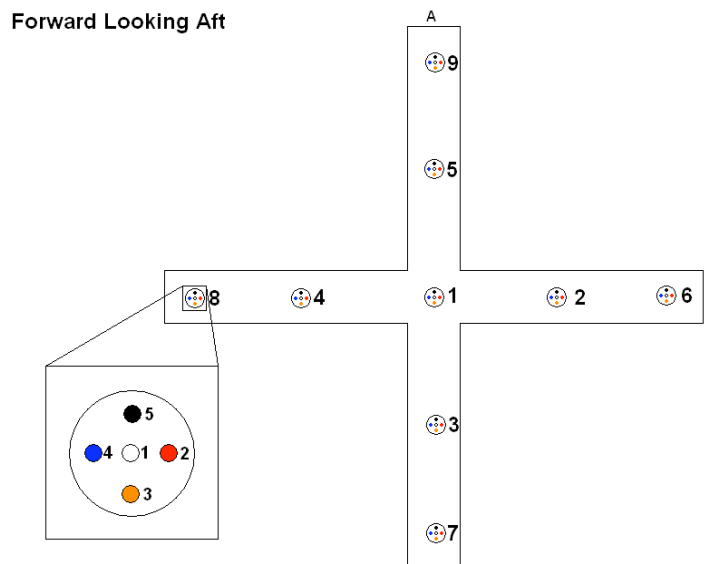

Figure 4. The Rake Airflow Gauge Experiment probe and port numbering conventions. 


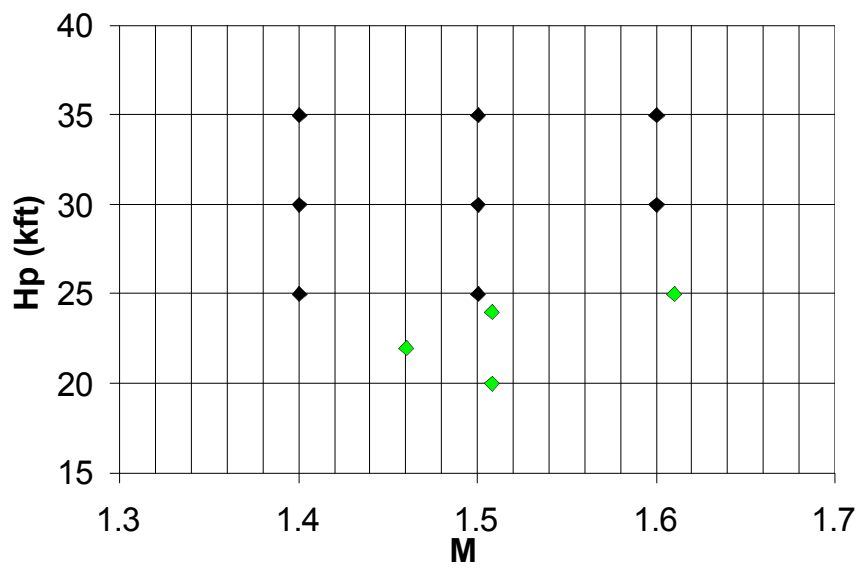

Figure 5. Flight-test (black) and wind-tunnel calibration (green) conditions: pressure altitude versus Mach number.

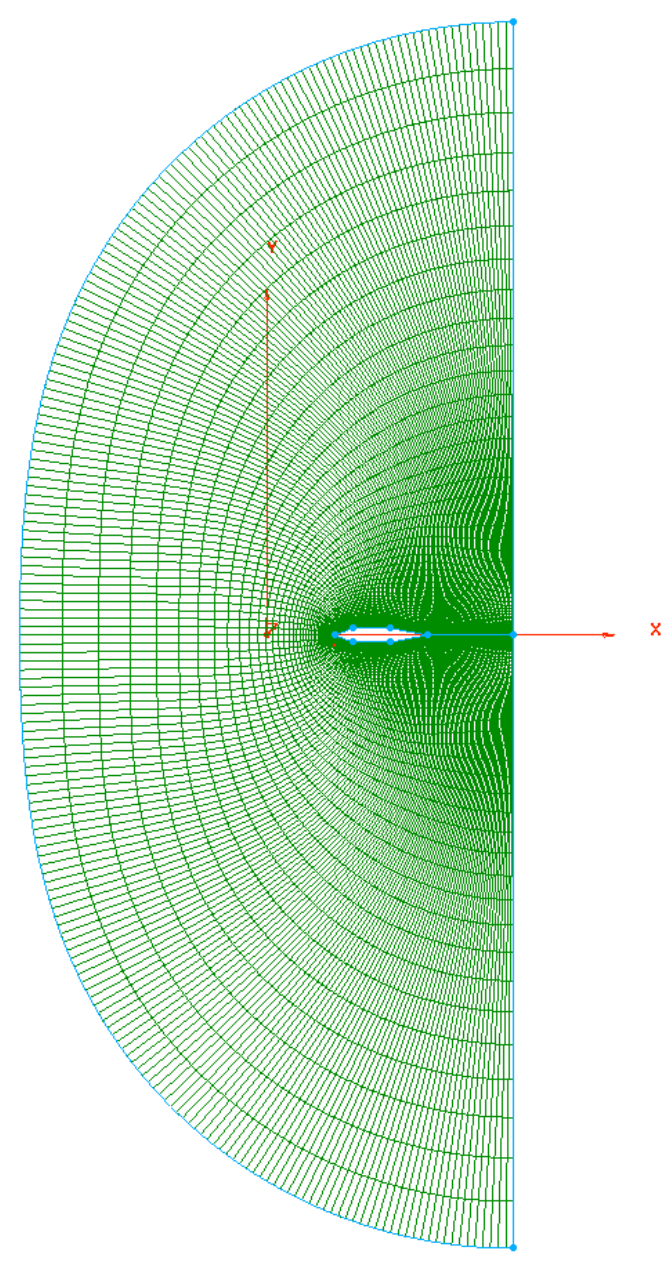

Figure 6. The mesh used in WIND-US2 for the rake loads calculation. 




Figure 7. Contours of static pressure for the rake cross-section: $M a c h=1.5, \alpha=20^{\circ}$. 



a) The COSMOSWorks ${ }^{\mathrm{TM}}$ mesh.

b) The boundary conditions, looking fore to aft.

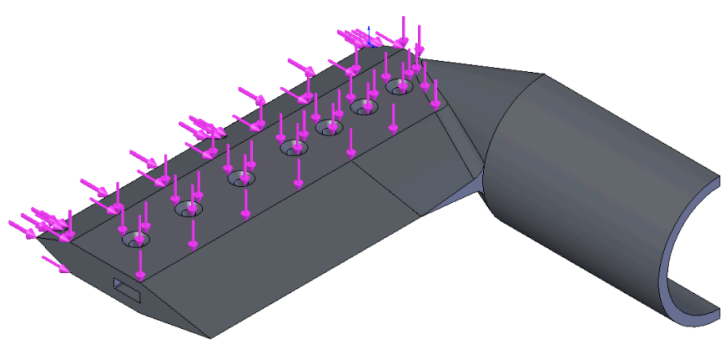

c) The applied axial and normal loads.

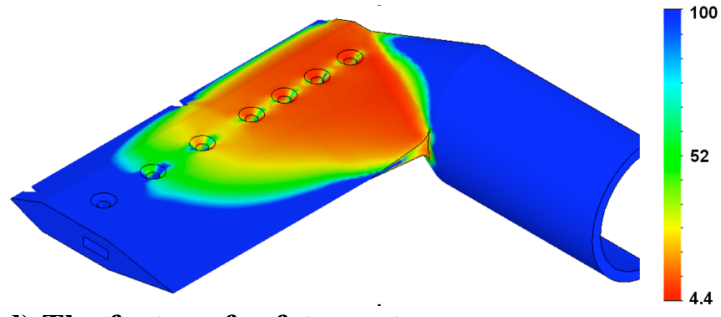

d) The factor of safety contours.

Figure 8. The finite element analysis for the rake stress calculation.

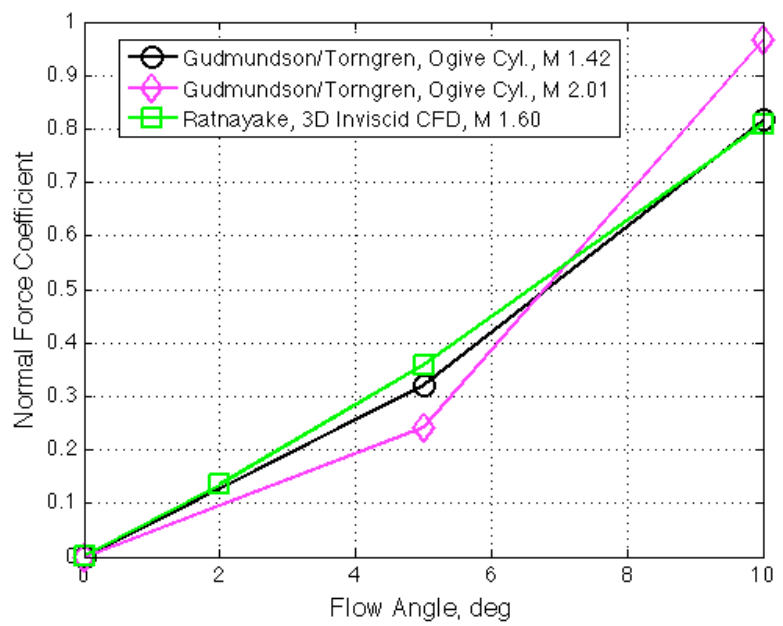

Figure 9. Probe 2D viscous computational fluid dynamics solution at Mach 1.6 versus experimental data for ogive cylinders; the normal force coefficient is corrected to the equivalent fineness ratio and wetted area. 


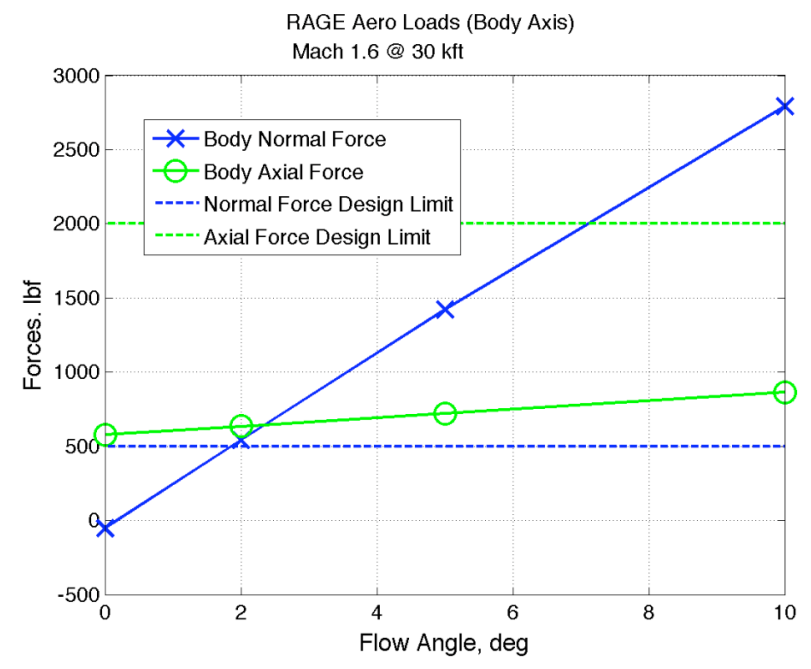

Figure 10. The rake and boom assembly body axis loads versus local flow angle, shown with associated design limits.

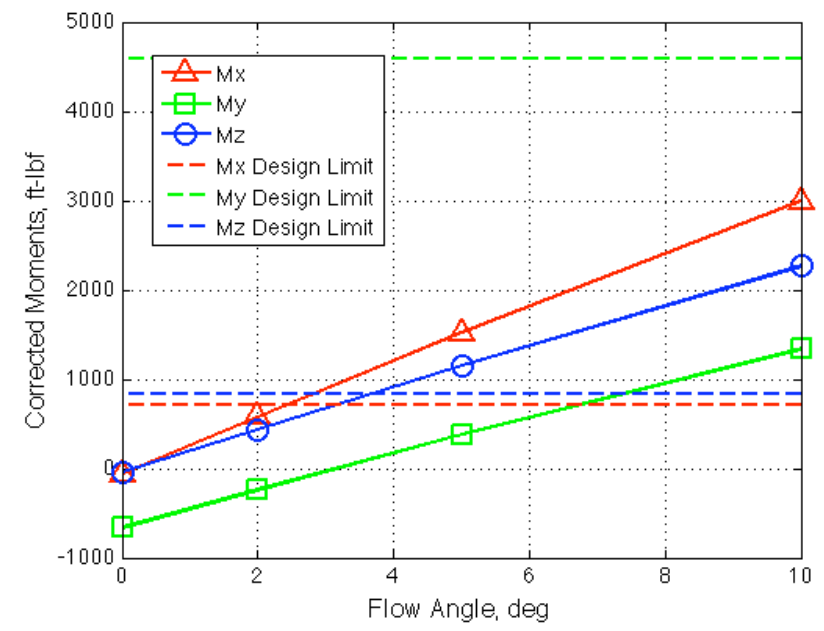

Figure 11. The rake and boom assembly moments versus local flow angle, corrected to the load limit test reference frame, and shown with associated design limits. 


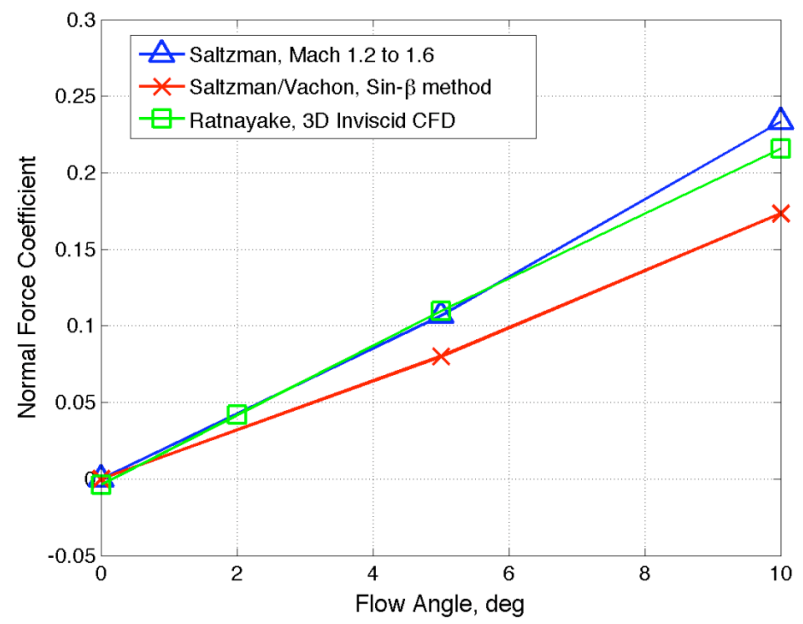

Figure 12. Comparison of assembly computational fluid dynamics to lower-order methods.
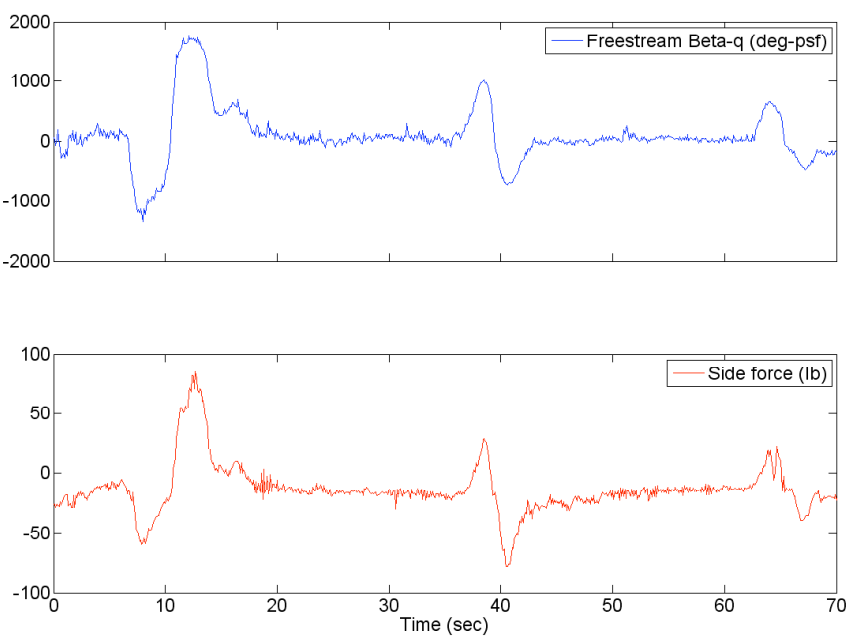

Figure 13. Beta-q and side-force flight data from Local Mach Investigation flights. 


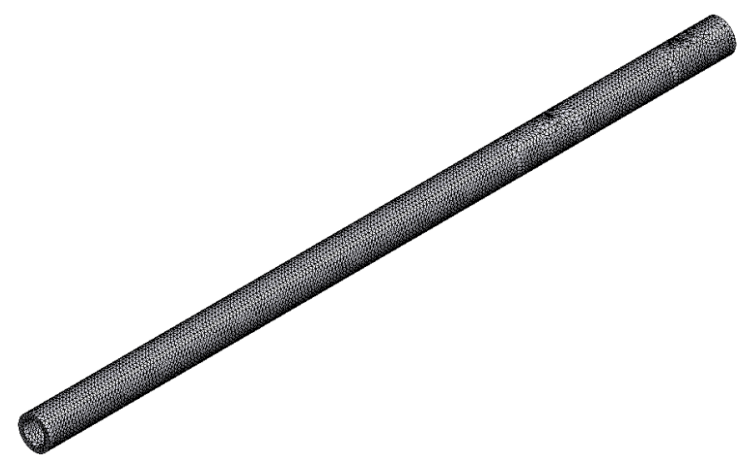

a) The boom mesh, created in COSMOSWorks ${ }^{\mathrm{TM}}$.



b) The factor of safety contours for the boom finite element analysis.

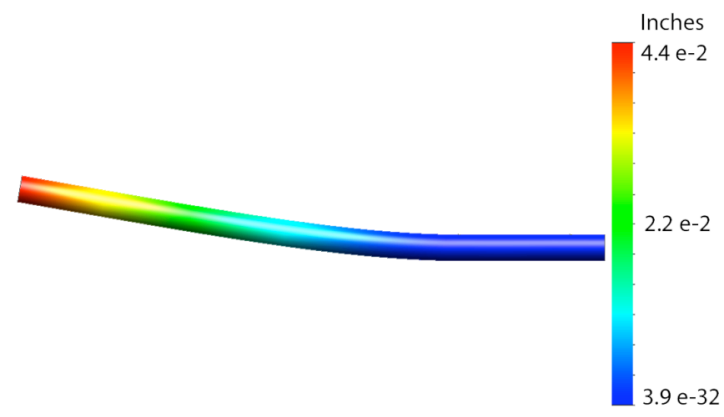

c) Deformed boom shape, magnified 25.4639 times.

Figure 14. The boom finite element analysis mesh and results. 


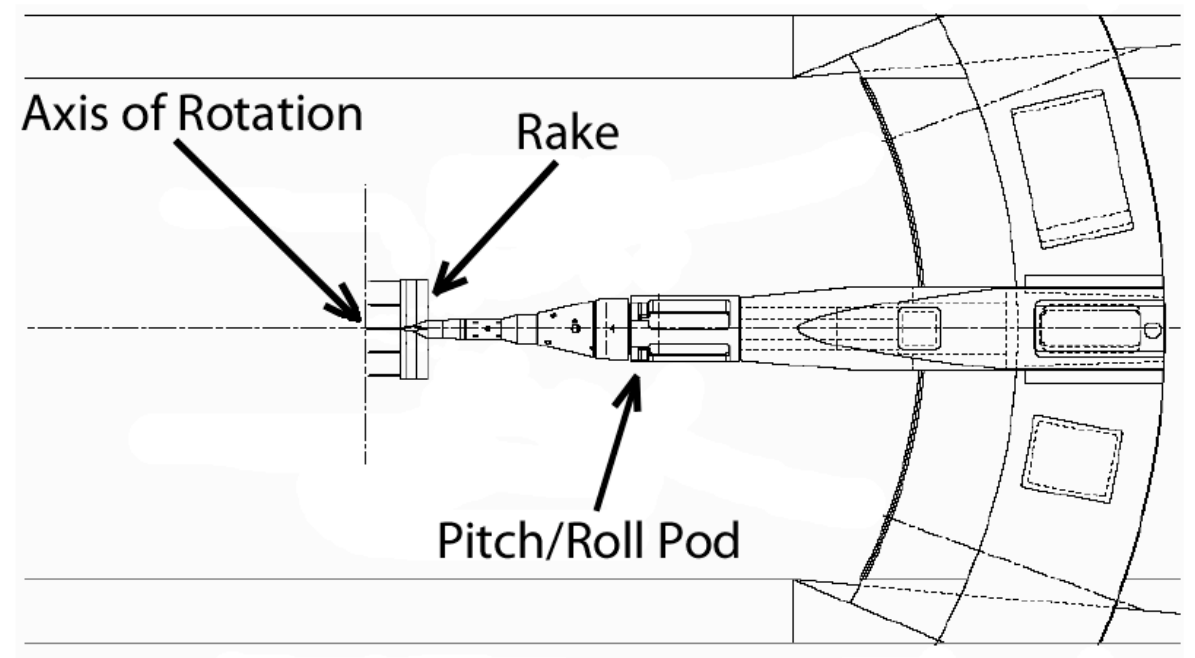

Figure 15. The wind tunnel: physical setup.

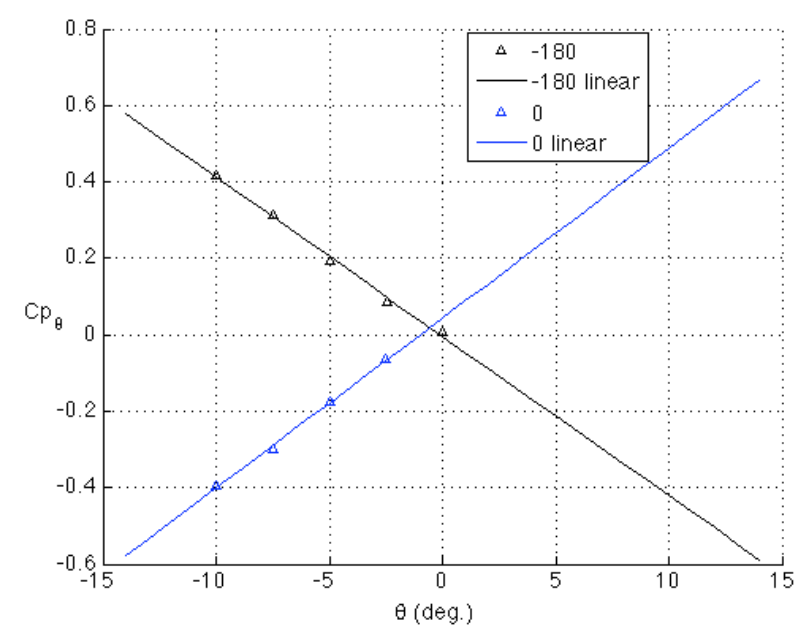

Figure 16. Probe 1 vertical misalignment; $M=1.461$. 


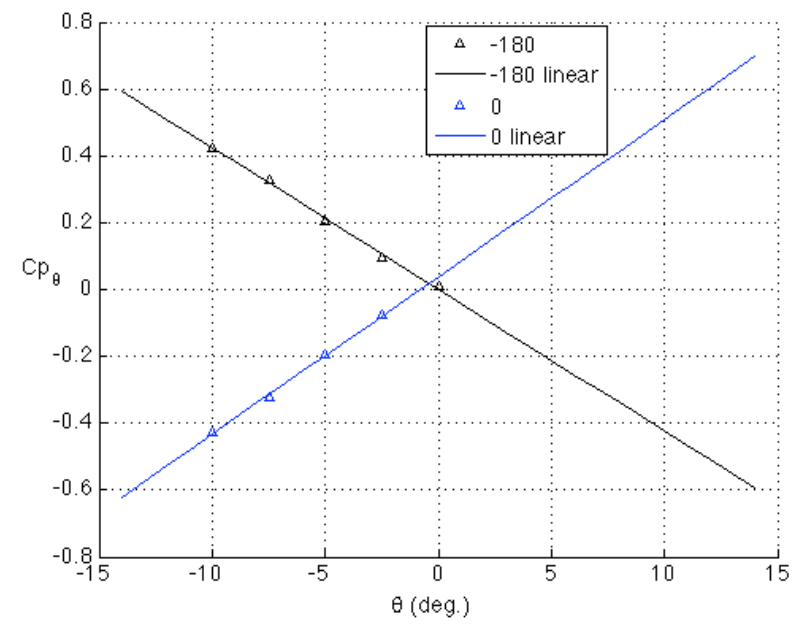

Figure 17. Probe 1 vertical misalignment; $M=1.508$.

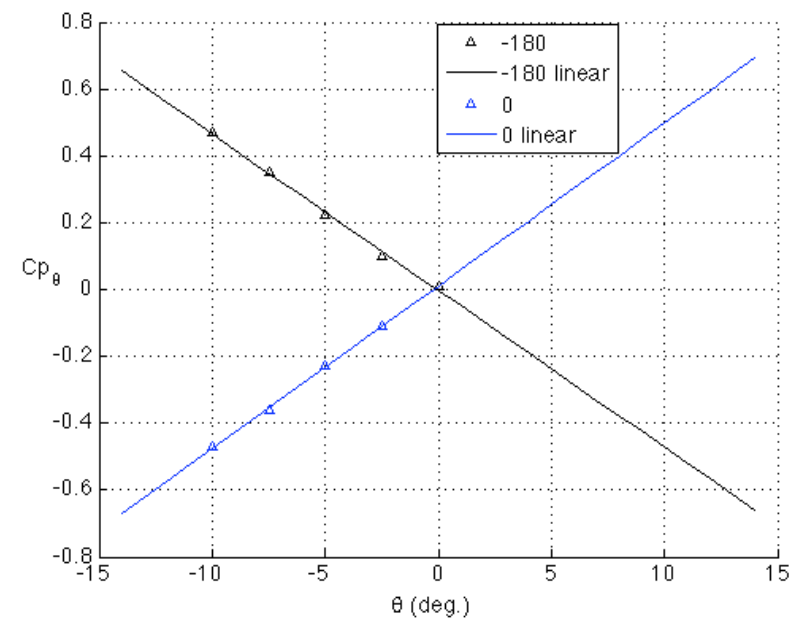

Figure 18. Probe 1 vertical misalignment; $M=1.611$.

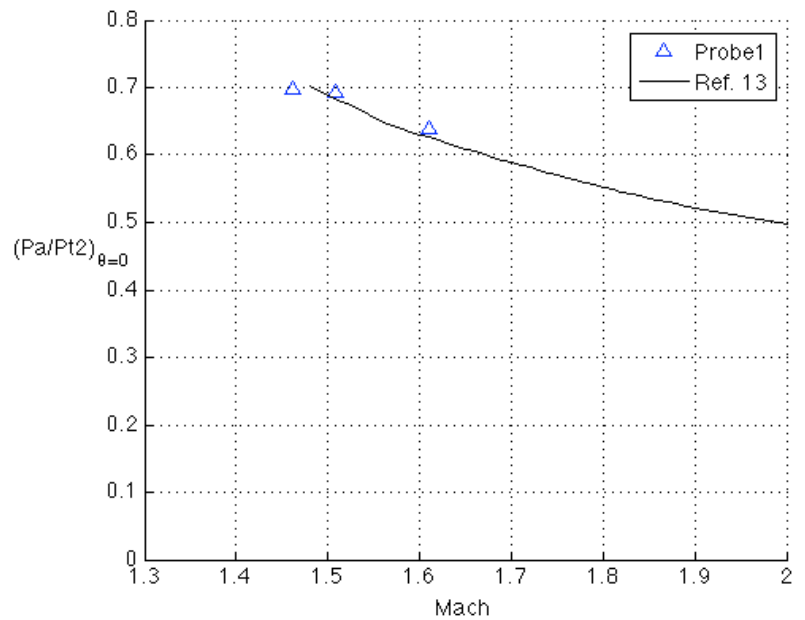

Figure 19. Probe 1 ratio of static to pitot pressure at zero flow inclination. 


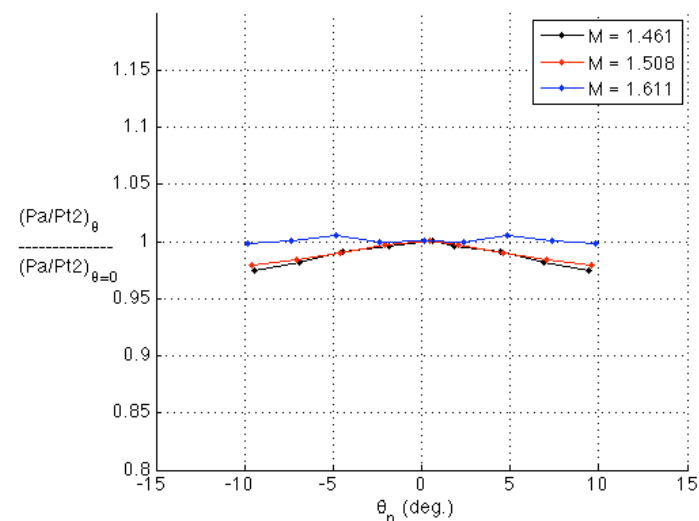

a) $\phi=-\mathbf{1 8 0}^{\circ}$.

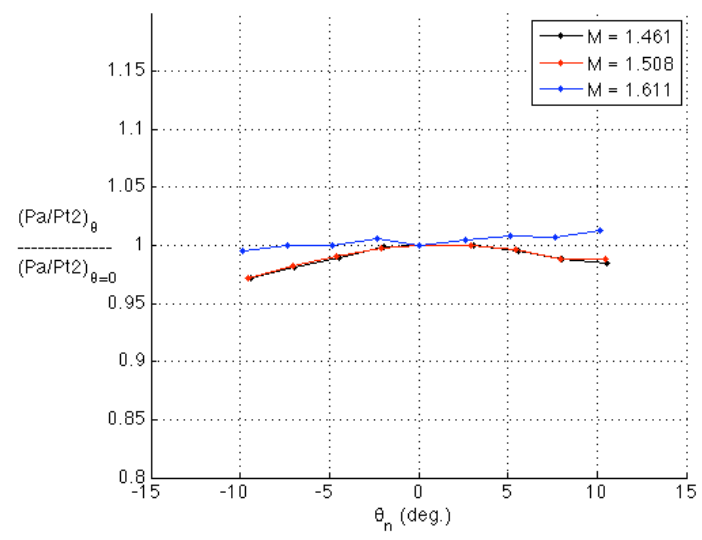

c) $\phi=-90^{\circ}$.

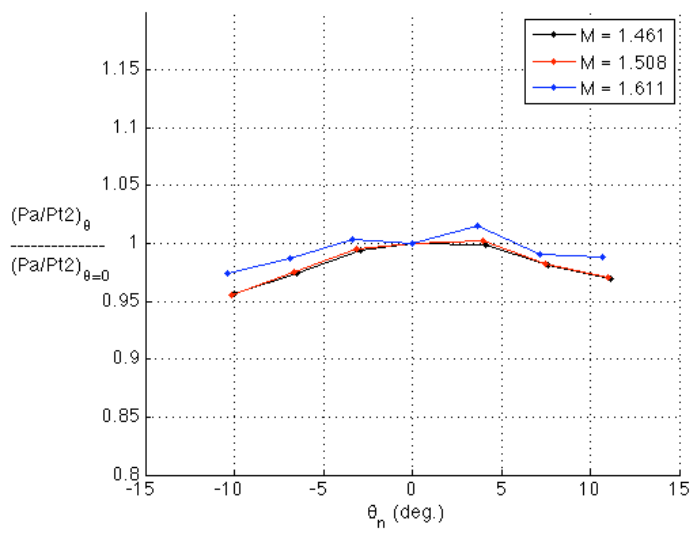

b) $\phi=-135^{\circ}$.

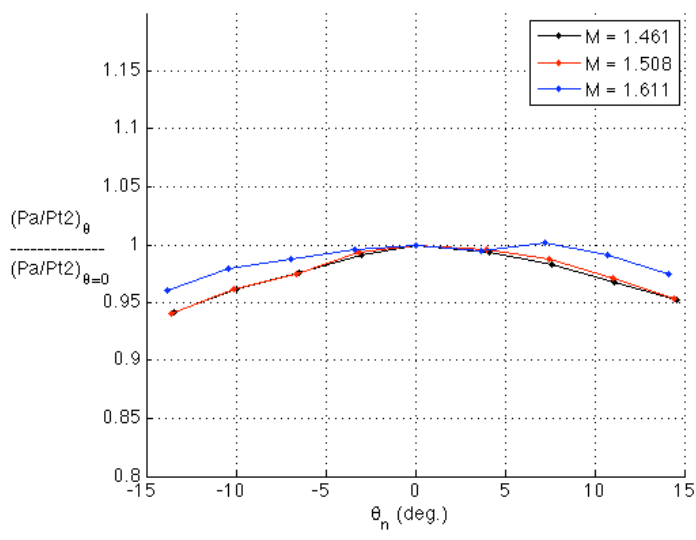

d) $\phi=-45^{\circ}$.

Figure 20. The effect of pitch angle on the ratio of static to pitot pressure, probe 1. 


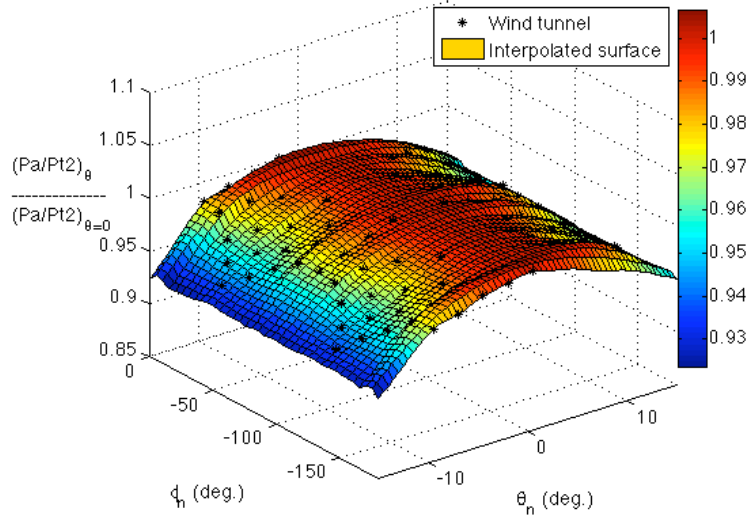

a) $\mathrm{M}=1.461$.



c) $\mathrm{M}=1.611$.

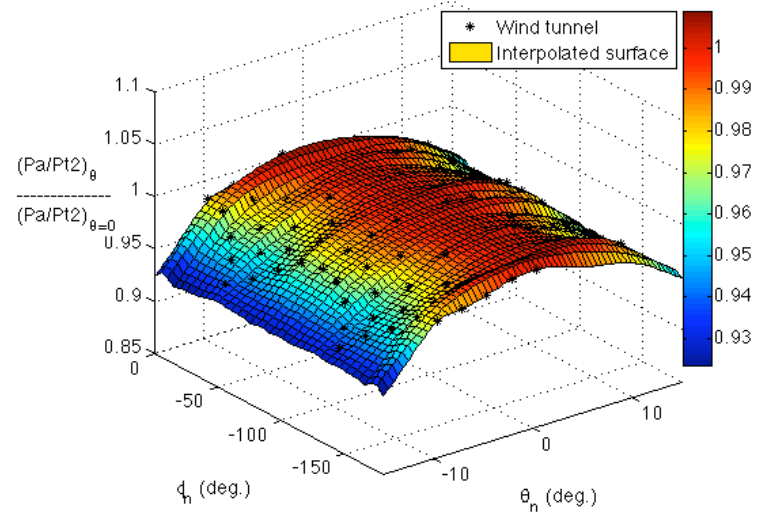

b) $\mathrm{M}=1.508$.

Figure 21. Probe 1 static-to-pitot-pressure ratio calibration maps.

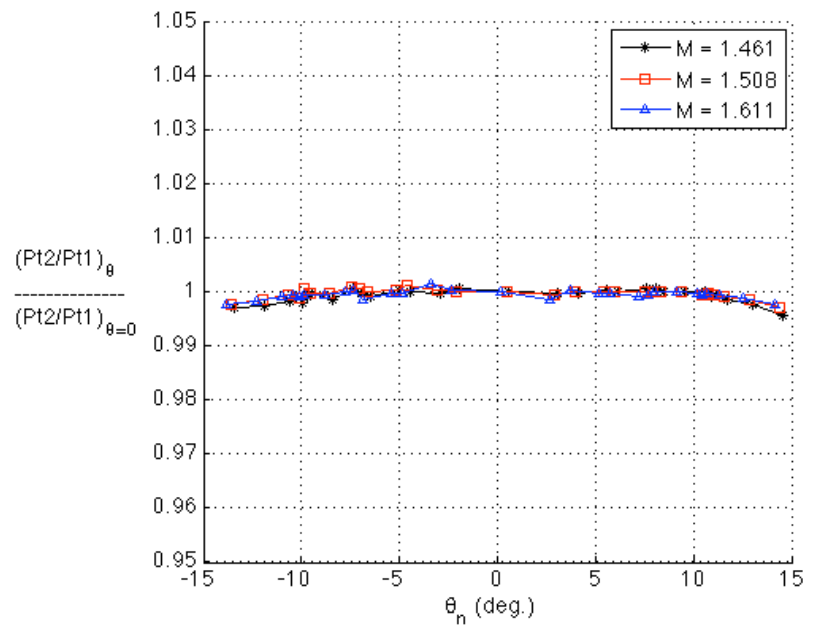

Figure 22. Effect of pitch angle on pitot-to-total-pressure ratio, probe 1 . 


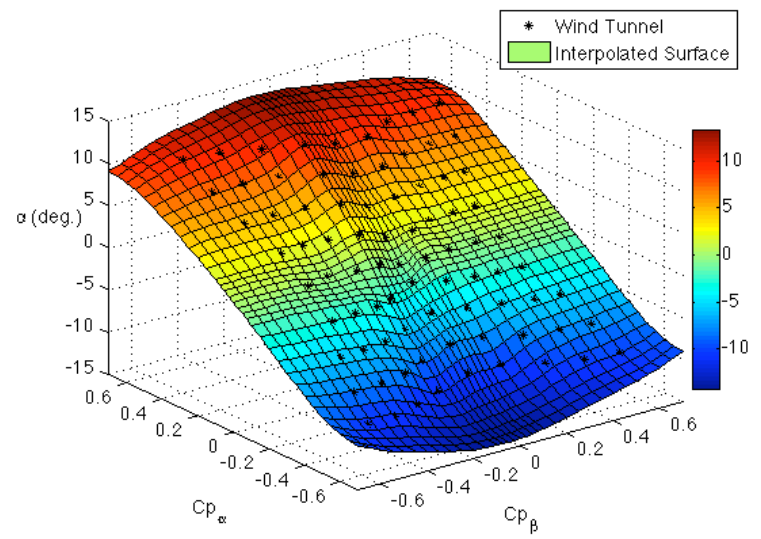

a) Angle of attack calibration, $M=1.461$.

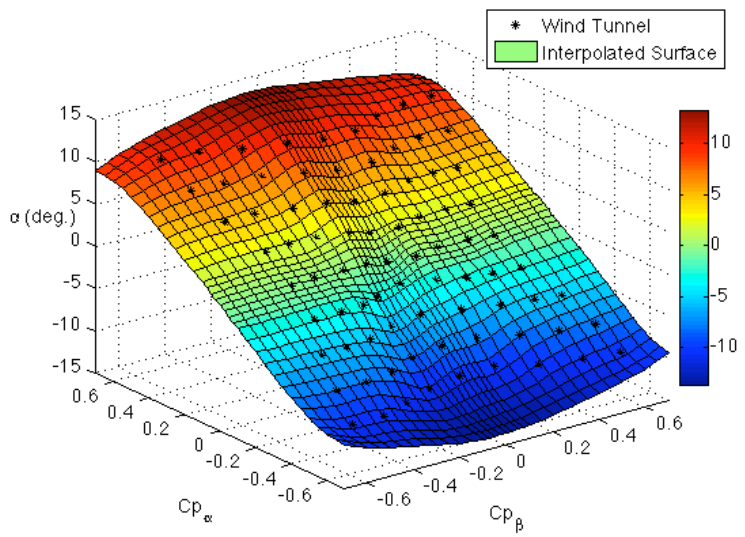

c) Angle of attack calibration, $M=1.508$.

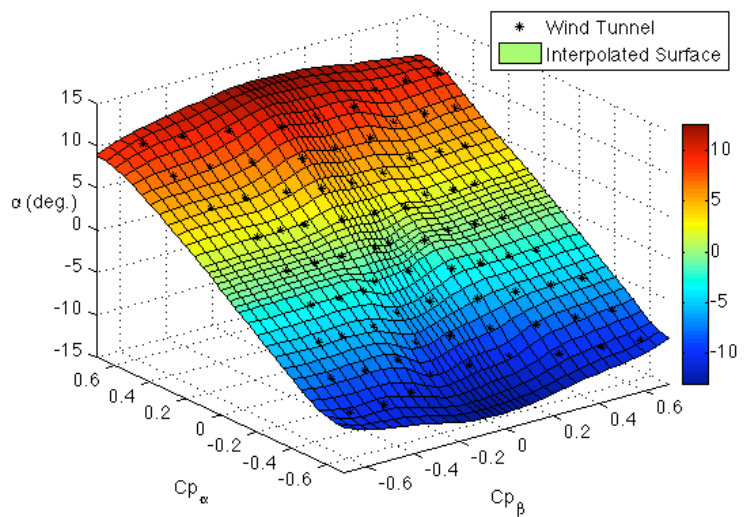

e) Angle of attack calibration, $M=1.611$.

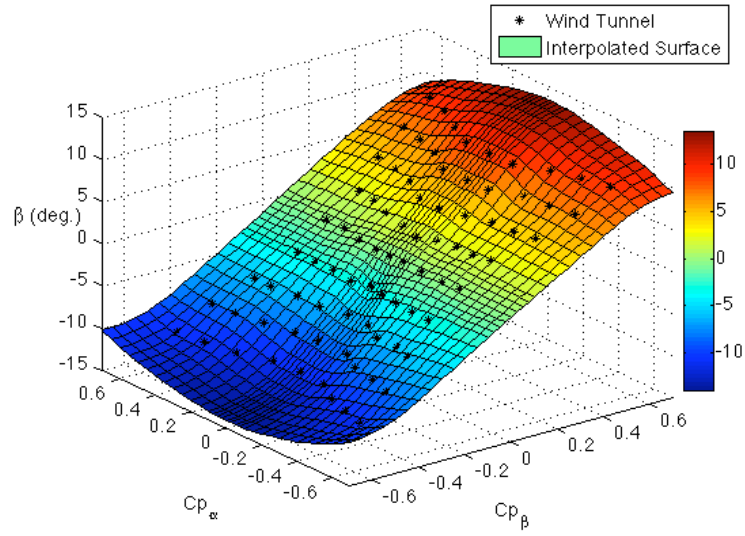

b) Angle of sideslip calibration, $\mathrm{M}=1.461$.

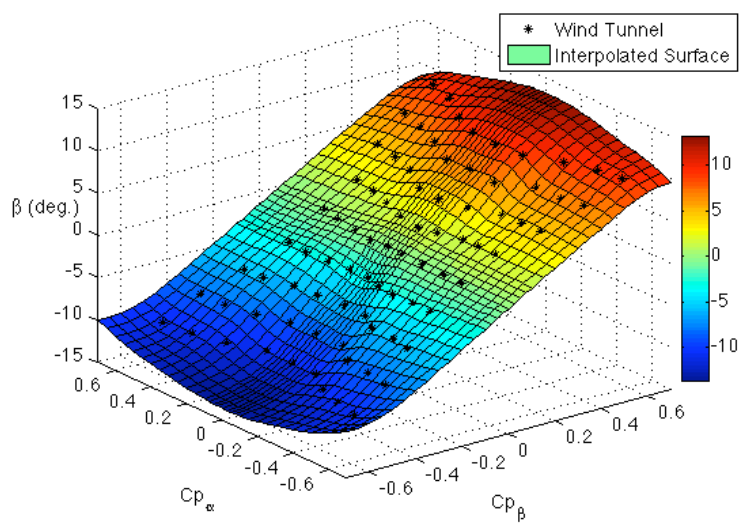

d) Angle of sideslip calibration, $M=1.508$.

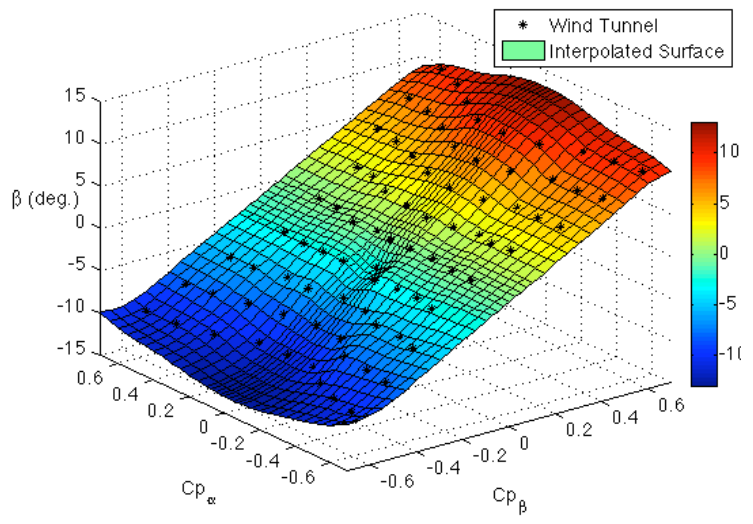

f) Angle of sideslip calibration, $M=1.611$.

Figure 23. Probe 1 flow angularity calibration maps. 